\title{
Posicionamento - Protocolo de Reconexão dos Serviços de Cardiologia com os Pacientes Durante a Pandemia de COVID-19 - 2020
}

\section{Statement - Protocol for the Reconnection of Cardiology Services with Patients During the COVID-19 Pandemic - 2020}

Realização: Sociedade Brasileira de Cardiologia

Conselho de Normatizações e Diretrizes (2020-2021): Brivaldo Markman Filho, Antonio Carlos Sobral Sousa, Aurora Felice Castro Issa, Bruno Ramos Nascimento, Harry Correa Filho, Marcelo Luiz Campos Vieira

Coordenador de Normatizações e Diretrizes (2020-2021): Brivaldo Markman Filho

Autores do Posicionamento: Marcio Sommer Bittencourt, ${ }^{1 \oplus}$ Giuliano Generoso, ${ }^{2}$ Pedro Henrique M. Craveiro de Melo, ${ }^{2 \oplus}$ Driele Peixoto, ${ }^{3 \oplus}$ Érique José Farias Peixoto de Miranda, ${ }^{4 \oplus}$ Evandro Tinoco Mesquita, ${ }^{5,6}$ Andréa Araujo Brandão, ${ }^{7 \oplus}$ José Francisco Kerr Saraiva, ${ }^{8 \oplus}$ Silvio Henrique Barberato, ${ }^{9}$ Fernando Bacal, ${ }^{10,11 \oplus}$ Marcelo Antônio Cartaxo Queiroga Lopes ${ }^{120}$

Hospital Universitário da Universidade de São Paulo (USP), ${ }^{1}$ São Paulo, SP - Brasil

Hospital Sírio Libanês, ${ }^{2}$ São Paulo, SP - Brasil

Instituto do Câncer do Estado de São Paulo (ICESP), ${ }^{3}$ São Paulo, SP - Brasil

Bayer Pharmaceuticals SA, ${ }^{4}$ São Paulo, SP - Brasil

Universidade Federal Fluminense (UFF), ${ }^{5}$ Niterói, RJ - Brasil

Centro de Ensino e Treinamento Edson de Godoy Bueno / UHG, ${ }^{6}$ Rio de Janeiro, RJ - Brasil

Faculdade de Ciências Médicas da Universidade do Estado do Rio de Janeiro (FCM/UERJ), ${ }^{7}$ Rio de Janeiro, RJ - Brasil

Sociedade Campineira de Educação e Instrução, ${ }^{8}$ campinas, SP - Brasil

CardioEco Centro de Diagnóstico Cardiovascular, ${ }^{9}$ Curitiba, PR - Brasil

Instituto do Coração do Hospital das Clínicas da Faculdade de Medicina da Universidade de São Paulo, ${ }^{10}$ São Paulo, SP - Brasil

Hospital Israelita Albert Einstein, ${ }^{11}$ São Paulo, SP - Brasil

Hospital Alberto Urquiza Wanderley, ${ }^{12}$ João Pessoa, PB - Brasil

Este posicionamento deverá ser citado como:

Bittencourt MS, Generoso G, Melo PHMC, Peixoto D, Miranda EJFP, Mesquita ET, et al. Posicionamento - Protocolo de Reconexão dos Serviços de Cardiologia com os Pacientes Durante a Pandemia de COVID-19 - 2020. Arq Bras Cardiol. 2020; 115(4):776-799

Nota: Estes Posicionamentos se prestam a informar e não a substituir o julgamento clínico do médico que, em última análise, deve determinar o tratamento apropriado para seus pacientes.

Correspondência: Sociedade Brasileira de Cardiologia - Av. Marechal Câmara, 360/330 - Centro - Rio de Janeiro - CEP: $20020-907$.

E-mail: diretrizes@cardiol.br 
Posicionamento - Protocolo de Reconexão dos Serviços de Cardiologia com os Pacientes Durante a Pandemia de COVID-19 - 2020

O relatório abaixo lista as declarações de conflito de interesse conforme relatadas à SBC pelos especialistas durante o período de desenvolvimento desta diretriz, 2020.

\begin{tabular}{|c|c|}
\hline Especialista & Tipo de relacionamento com a indústria \\
\hline Andréa Araujo Brandão & $\begin{array}{l}\text { DECLARAÇÃO FINANCEIRA } \\
\text { A - PAGAMENTO DE QUALQUER ESPÉCIE E DESDE QUE ECONOMICAMENTE APRECIÁVEIS, FEITOS A (i) VOCÊ, (ii) AO } \\
\text { SEU CÔNJUGEICOMPANHEIRO OU A QUALQUER OUTRO MEMBRO QUE RESIDA COM VOCÊ,, (iii) A QUALQUER PESSOA } \\
\text { JURIDICA EM QUE QUALQUER DESTES SEJA CONTROLADOR, SÓCIO, ACIONISTA OU PARTICIPANTE, DE FORMA } \\
\text { DIRETA OU INDIRETA, RECEBIMENTO POR PALESTRAS, AULAS, ATUAÇÃO COMO PROCTOR DE TREINAMENTOS, } \\
\text { REMUNERAÇÕES, HONORÁRIOS PAGOS POR PARTICIPAÇÕES EM CONSELHOS CONSULTIVOS, DE INVESTIGADORES, } \\
\text { OU OUTROS COMITÊS, ETC. PROVENIENTES DA INDÚSTRIA FARMACÊUTICA, DE ÓRTESES, PRÓTESES, EQUIPAMENTOS } \\
\text { E IMPLANTES, BRASILEIRAS OU ESTRANGEIRAS: } \\
\text { - Servier: Palestras } \\
\text { - Libbs: Hipertensão arterial } \\
\text { - Novartis: Insuficiência cardiaca } \\
\text { - EMS: Hipertensão arterial } \\
\text { - Sandoz: Hipertensão arterial } \\
\text { - Abbott: Hipertensão arterial } \\
\text { OUTROS RELACIONAMENTOS: } \\
\text { FINANCIAMENTO DE ATIVIDADES DE EDUCAÇÃO MÉDICA CONTINUADA, INCLUINDO VIAGENS, HOSPEDAGENS } \\
\text { E INSCRIÇÕES PARA CONGRESSOS E CURSOS, PROVENIENTES DA INDÚSTRIA FARMACÉUTICA, DE ÓRTESES, } \\
\text { PRÓTESES, EQUIPAMENTOS E IMPLANTES, BRASILEIRAS OU ESTRANGEIRAS: } \\
\text { - Servier: Hipertensão arterial }\end{array}$ \\
\hline Driele Peixoto & Nada a ser declarado \\
\hline $\begin{array}{l}\text { Érique José Farias } \\
\text { Peixoto de Miranda, }\end{array}$ & $\begin{array}{l}\text { DECLARAÇÃO FINANCEIRA } \\
\text { A - PAGAMENTO DE QUALQUER ESPÉCIE E DESDE QUE ECONOMICAMENTE APRECIÁVEIS, FEITOS A (i) VOCÊ, (ii) AO } \\
\text { SEU CÔNJUGE/COMPANHEIRO OU A QUALQUER OUTRO MEMBRO QUE RESIDA COM VOCÊ, (iii) A QUALQUER PESSOA } \\
\text { JURÍDICA EM QUE QUALQUER DESTES SEJA CONTROLADOR, SÓCIO, ACIONISTA OU PARTICIPANTE, DE FORMA } \\
\text { DIRETA OU INDIRETA, RECEBIMENTO POR PALESTRAS, AULAS, ATUAÇÃO COMO PROCTOR DE TREINAMENTOS, } \\
\text { REMUNERAÇÕES, HONORÁRIOS PAGOS POR PARTICIPAÇÕES EM CONSELHOS CONSULTIVOS, DE INVESTIGADORES, } \\
\text { OU OUTROS COMITÉS, ETC. PROVENIENTES DA INDÚSTRIA FARMACÊUTICA, DE ÓRTESES, PRÓTESES, EQUIPAMENTOS } \\
\text { E IMPLANTES, BRASILEIRAS OU ESTRANGEIRAS:w } \\
\text { - Bayer: XareIto } \\
\text { OUTROS RELACIONAMENTOS } \\
\text { VÍNCULO EMPREGATÍCIO COM A INDÚSTRIA FARMACÊUTICA, DE ÓRTESES, PRÓTESES, } \\
\text { EQUIPAMENTOS E IMPLANTES, BRASILEIRAS OU ESTRANGEIRAS, ASSIM COMO SE TEM } \\
\text { RELAÇÃO VÍNCULO EMPREGATICIO COM OPERADORAS DE PLANOS DE SAÚDE OU EM } \\
\text { AUDITORIAS MÉDICAS (INCLUINDO MEIO PERIODO) DURANTE O ANO PARA O QUAL VOCÊ ESTÁ DECLARANDO: } \\
\text { - Bayer }\end{array}$ \\
\hline Evandro Tinoco Mesquita & $\begin{array}{l}\text { OUTROS RELACIONAMENTOS } \\
\text { VÍNCULO EMPREGATÍCIO COM A INDÚSTRIA FARMACÊUTICA, DE ÓRTESES, PRÓTESES, } \\
\text { EQUIPAMENTOS E IMPLANTES, BRASILEIRAS OU ESTRANGEIRAS, ASSIM COMO SE TEM } \\
\text { RELAÇÃO VÍNCULO EMPREGATÍCIO COM OPERADORAS DE PLANOS DE SAÚDE OU EM } \\
\text { AUDITORIAS MÉDICAS (INCLUINDO MEIO PERIODO) DURANTE O ANO PARA O QUAL VOCÊ ESTÁ DECLARANDO: } \\
\text { - UnitedHealth Group }\end{array}$ \\
\hline Fernando Bacal & $\begin{array}{l}\text { DECLARAÇÃO FINANCEIRA } \\
\text { A - PAGAMENTO DE QUALQUER ESPÉCIE E DESDE QUE ECONOMICAMENTE APRECIÁVEIS, FEITOS A (i) VOCÊ, (ii) AO } \\
\text { SEU CÔNJUGEICOMPANHEIRO OU A QUALQUER OUTRO MEMBRO QUE RESIDA COM VOCÊ,, (iii) A QUALQUER PESSOA } \\
\text { JURIDICA EM QUE QUALQUER DESTES SEJA CONTROLADOR, SÓCIO, ACIONISTA OU PARTICIPANTE, DE FORMA } \\
\text { DIRETA OU INDIRETA, RECEBIMENTO POR PALESTRAS, AULAS, ATUAÇÃO COMO PROCTOR DE TREINAMENTOS, } \\
\text { REMUNERAÇÕES, HONORÁRIOS PAGOS POR PARTICIPAÇÕES EM CONSELHOS CONSULTIVOS, DE INVESTIGADORES, } \\
\text { OU OUTROS COMITÊS, ETC. PROVENIENTES DA INDÚSTRIA FARMACÊUTICA, DE ÓRTESES, PRÓTESES, EQUIPAMENTOS } \\
\text { E IMPLANTES, BRASILEIRAS OU ESTRANGEIRAS } \\
\text { - Novartis: Entresto }\end{array}$ \\
\hline Giuliano Generoso & Nada a ser declarado \\
\hline $\begin{array}{l}\text { José Francisco Kerr } \\
\text { Saraiva }\end{array}$ & Nada a ser declarado \\
\hline $\begin{array}{l}\text { Marcelo Antônio Cartaxo } \\
\text { Queiroga Lopes }\end{array}$ & ada a ser declarado \\
\hline
\end{tabular}


Bittencourt et al.

Posicionamento - Protocolo de Reconexão dos Serviços de Cardiologia com os Pacientes

Durante a Pandemia de COVID-19 - 2020

\section{Posicionamento}

\begin{tabular}{ll}
\hline & DECLARAÇÃO FINANCEIRA \\
\hline & A - PAGAMENTO DE QUALQUER ESPÉCIE E DESDE QUE ECONOMICAMENTE APRECIÁVEIS, FEITOS A (i) VOCÊ, (ii) AO \\
& SEU CÔNJUGE/COMPANHEIRO OU A QUALQUER OUTRO MEMBRO QUE RESIDA COM VOCÊ, (iii) A QUALQUER PESSOA \\
& JURIDICA EM QUE QUALQUER DESTES SEJA CONTROLADOR, SÓCIO, ACIONISTA OU PARTICIPANTE, DE FORMA \\
& DIRETA OU INDIRETA, RECEBIMENTO POR PALESTRAS, AULAS, ATUAÇÃO COMO PROCTOR DE TREINAMENTOS, \\
& REMUNERAÇÕES, HONORÁRIOS PAGOS POR PARTICIPAÇÕES EM CONSELHOS CONSULTIVOS, DE INVESTIGADORES, \\
& OU OUTROS COMITÊS, ETC. PROVENIENTES DA INDÚSTRIA FARMACÊUTICA, DE ÓRTESES, PRÓTESES, \\
& EQUIPAMENTOS E IMPLANTES, BRASILEIRAS OU ESTRANGEIRAS: \\
& - Sanofi: Pesquisa \\
& - EMS: Palestras \\
& Novo Nordisk: Palestras \\
& C - FINANCIAMENTO DE PESQUISA (PESSOAL), CUJAS RECEITAS TENHAM SIDO PROVENIENTES DA INDÚSTRIA \\
& FARMACÉUTICA, DE ÓRTESES, PRÓTESES, EQUIPAMENTOS E IMPLANTES, BRASILEIRAS OU ESTRANGEIRAS: \\
& - Sanofi: Pesquisa \\
\hline Pedro Henrique M. Craveiro & Nada a ser declarado \\
de Melo & \\
\hline Silvio Henrique Barberato & Nada a ser declarado \\
\hline
\end{tabular}




\section{Sumário}

1. Introdução e Conceitos Gerais .779

2. Perfis do Atendimento, Clínico do Paciente e do Ambiente de Atendimento. .781

a. Orientações Gerais Aplicáveis a Todos os Ambientes de Atendimento ....781

b. Definição do Perfil de Atendimento Cardiológico Quanto à sua

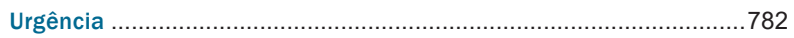

c. Definição do Perfil Clínico do Paciente (Status para COVID-19) ...........782

d. Definição do Ambiente de Atendimento .............................................783

3. Medidas de Precaução e Isolamento COVID-19 ............783

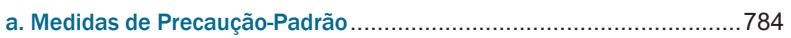

b. Medidas de Precaução contra Contato + Gotículas ............................784

c. Medidas de Precaução contra Contato + Aerossóis............................784

d. Recomendação de EPI de Acordo com a Complexidade dos Procedimentos e

o Perfil Clínico do Paciente ..................................................................785

e. Limpeza e Desinfecção de Superfícies .............................................786

4. Estratégia de Abordagem no Contexto do Ambiente de

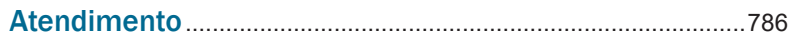

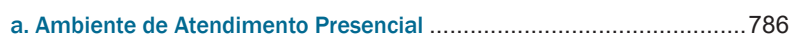

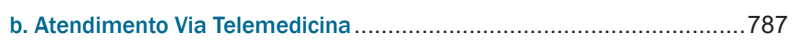

c. Acompanhamento Remoto ............................................................787

5. Estratégia de Abordagem no Contexto dos Exames

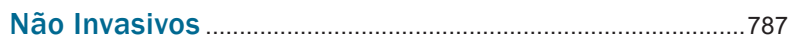

a. Métodos Gráficos em Cardiologia......................................................787

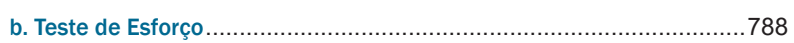

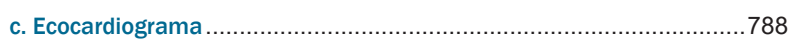

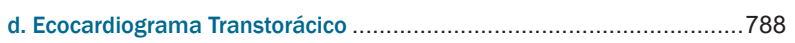

e. Ecocardiograma Transesofágico ...................................................788

f. Ecocardiograma de Estresse .........................................................789

g. Tomografia Computadorizada e Ressonância Magnética do Coração .....790

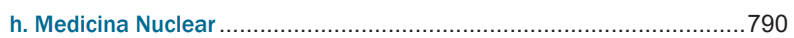

6. Hemodinâmica e Cardiologia Intervencionista ..............791

a. Procedimentos Eletivos................................................................ 791

b. Procedimentos de Urgência e Emergência ..........................................793

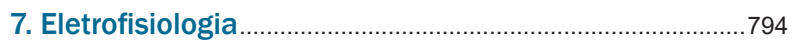

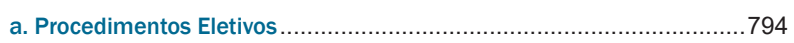

b. Procedimentos de Urgência e Emergência .........................................794

8.Considerações Especiais Acerca dos Pacientes Envolvidos no Transplante Cardíaco...............................................................794

9. Orientações ao Paciente com Fatores de Risco para Infecção por SARS-CoV-2 e suas Repercussões Clínicas.

10. Segurança dos Pacientes e Profissionais de Saúde

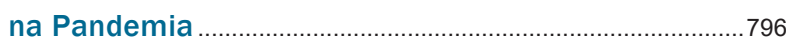

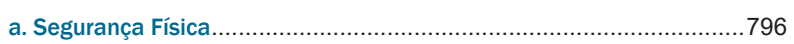

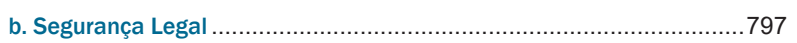

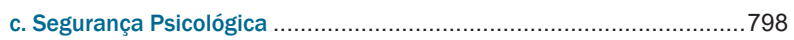

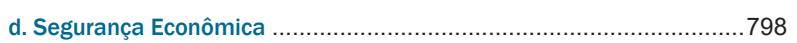

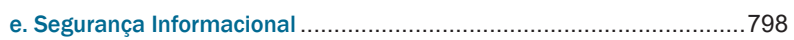

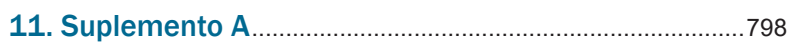

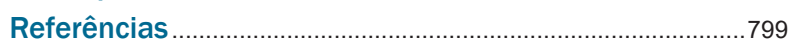

\section{Introdução e Conceitos Gerais}

A pandemia resultante da infecção pelo novo coronavírus (SARS-CoV-2), denominada COVID-19, teve início em Wuhan, na China, em dezembro de 2019.1,2 Já acometeu milhões de pessoas em todo o mundo, resultando em centenas de milhares de mortes.

A transmissão do vírus ocorre principalmente de pessoa a pessoa ${ }^{1,2}$ de forma direta pelas vias respiratórias ou pelo contato indireto com superfícies e objetos contaminados. As infecções respiratórias acontecem através da transmissão de gotículas contendo vírus ( $>5 \mu \mathrm{m}$ com extensão aproximada de $1,5 \mathrm{~m}$ ) ou aerossóis ( $\leq 5 \mu \mathrm{m}$ com extensão aproximada de $8 \mathrm{~m}$ ) exalados por indivíduos infectados. ${ }^{3,4}$ Dados recentes sugerem possível transmissão pelo ar. O contato de gotículas respiratórias contaminadas, eliminadas pela respiração, fala, espirro e tosse de pessoas infectadas, com as mucosas de olhos, boca e nariz de indivíduos suscetíveis resulta na transmissão do SARS-CoV-2. Com a expansão da pandemia de COVID-19 e o rápido aumento de casos, estudos demonstraram a viabilidade do vírus no ambiente e o papel das superfícies contaminadas na transmissão hospitalar da COVID-19. ${ }^{5}$ Com base na transmissão por gotículas, os Centros para Controle e Prevenção de Doenças dos Estados Unidos recomendam distanciamento físico de no mínimo 1,5 m e higienização das mãos para redução da propagação do vírus.

A apresentação clínica da COVID-19 pode variar desde uma forma leve a moderada, que é mais frequente e acomete $80 \%$ dos casos, até uma mais grave, que acomete os outros 20\% com quadro comparável ao que no Brasil se define como síndrome respiratória aguda grave (SRAG). ${ }^{6}$ Os sintomas mais sensíveis da forma leve/moderada são tosse não produtiva e febre, que pode ou não ocorrer no momento da apresentação, ao passo que os mais específicos são alteração do olfato e do paladar. ${ }^{7,8}$ A SRAG é definida como uma síndrome gripal (SG) associada a dispneia/desconforto respiratório ou pressão persistente no tórax ou saturação de $\mathrm{O}_{2}$ menor que 95\% em ar ambiente ou coloração azulada dos lábios ou rosto, com taquipneia, cianose e grave acometimento pulmonar.

Devido ao potencial de disseminação do vírus, à apresentação clínica grave em uma parte dos casos e à inexistência de tratamento viral específico, ou mesmo de vacina, medidas não farmacológicas são as intervenções mais eficazes até o presente momento. ${ }^{9,10}$ Essas intervenções não farmacológicas têm como objetivo reduzir a transmissão interpessoal do vírus por diminuição do contato entre infectados e suscetíveis, quer seja por aumento da distância entre as pessoas, redução da intensidade e da duração do contato, quer seja pelo uso de medidas e dispositivos físicos ou químicos que impeçam a passagem do vírus de uma pessoa para outra.

As intervenções não farmacológicas podem ser divididas em:

- Distanciamento físico: consiste no afastamento físico de no mínimo 2,0 m entre os indivíduos, tendo como exemplo o fechamento de escolas e de espaços de alta concentração de pessoas e restrição de viagens.

- Medidas de bloqueio de transmissão: higienização das mãos com água e sabão ou álcool, etiqueta da tosse e utilização de máscaras ou outras barreiras físicas de contato. 
- Identificação e isolamento de casos suspeitos ou confirmados: manter os casos em isolamento individual.

- Quarentena de contatos: rastreamento ativo dos contatos do caso e instituição de isolamento social, além de observação da evolução clínica para casos suspeitos.

Infelizmente, a população sofre as repercussões dessa crise humanitária não apenas pela COVID-19, como também pelos danos colaterais associados a atrasos e redução no atendimento de outras doenças em ambiente de prontosocorro, redução do acesso a cuidados de doenças crônicas em ambiente ambulatorial e maior exposição aos fatores de risco para o desenvolvimento de doenças (sedentarismo, obesidade, ansiedade e estresse emocional). Somem-se a isso perdas econômicas, impacto psicológico e burnout associado à pandemia. São duas as principais circunstâncias em que ocorre essa diminuição no cuidado adequado à saúde. Primeiro, há redução de consultas médicas e exames de rotina. Essa disrupção no atendimento de pacientes crônicos pode levar a descompensação aguda de condições como hipertensão arterial, diabetes e insuficiência cardíaca. Da mesma forma, podem ser enfrentadas consequências graves relacionadas à redução da procura e à demora no atendimento hospitalar de urgência e emergência em circunstâncias como síndromes coronarianas agudas, insuficiência cardíaca aguda e acidentes vasculares encefálicos. ${ }^{11-13}$

Buscando minimizar essas adversidades, a Sociedade Brasileira de Cardiologia (SBC) compilou orientações baseadas em evidências recentes, mesmo que limitadas e por vezes fundamentadas em opiniões de especialistas ou relatos preliminares, para criar um direcionamento estruturado visando à reconexão do médico com os pacientes de forma planejada na reabertura de serviços de cardiologia. Tal direcionamento tem por objetivo diminuir o risco tanto para pacientes e acompanhantes quanto para profissionais de saúde envolvidos nas atividades clínicas da Cardiologia.

As recomendações contidas neste documento são baseadas nas evidências disponíveis no momento da sua elaboração e na opinião de especialistas. O conhecimento em relação à COVID-19 evolui de forma dinâmica e rápida, logo, os protocolos para reintrodução com segurança de atendimentos médicos, procedimentos invasivos e procedimentos não invasivos estão em constante evolução e adaptação. Este projeto foi idealizado pela SBC como uma fonte de referência para seus associados. As recomendações apresentadas, contudo, não devem ser usadas como única base para a definição de protocolos locais, devendo outras fontes atualizadas ser consideradas à medida que o conhecimento na área evolui.

O presente posicionamento busca alinhar as seguintes demandas:

- Minimizar o risco de transmissão do SARS-CoV-2 entre pacientes, profissionais de saúde e outros envolvidos no atendimento.

- Identificar precocemente casos suspeitos de COVID-19 e implementar procedimento de triagem para atribuir níveis adequados de atendimento, reduzir o risco de complicações da COVID-19 e das doenças cardiovasculares presentes, assim como diminuir o risco de transmissão.
- Fornecer informações sobre cuidados relacionados à COVID-19 de maneira segura e confiável para pacientes e profissionais de saúde.

- Reduzir os impactos negativos nos pronto-atendimentos e internações hospitalares pela falta do tratamento ambulatorial de condições pré-existentes.

- Otimizar a utilização de equipamento de proteção individual (EPI).

Assim, para promover atendimento de excelência, mantendo a segurança do profissional de saúde e do paciente com doença cardiovascular, devemos admitir as seguintes premissas:

- Como a apresentação clínica é variável, a definição da presença ou ausência de infecção por SARS-CoV-2 pode não ser possível apenas com a avaliação clínica inicial. Protocolos claros de triagem devem ser utilizados para minimizar o risco de pacientes suspeitos circularem no ambiente de saúde, salvo para atendimento de urgência ou emergência. Caso necessária, essa circulação deve acontecer com o menor risco de contaminação possível.

- Todos os profissionais de saúde devem ser continuadamente treinados com relação a boas práticas, protocolos institucionais e fluxogramas de atendimento.

- Os atendimentos de emergência devem seguir o mesmo protocolo dos cuidados com pacientes com COVID-19 confirmada/suspeita, pois não é possível descartar COVID-19 em tempo hábil para o atendimento adequado, que deve continuar disponível em sua capacidade total.

- Os procedimentos eletivos e semi-eletivos serão retomados após planejamento, em menor escala do que sua capacidade prévia, com reavaliação contínua de comitê diretor responsável, sempre respeitando as autorizações e eventuais restrições à circulação, com abertura de serviços médicos definida pelas autoridades competentes.

- As rotas de acesso aos equipamentos diagnósticos devem ser destacadas para os serviços de transporte e indicadas para pacientes e demais funcionários que não pertençam ao setor médico de atendimento com o objetivo de minimizar o contato entre profissionais da saúde e pacientes e a sua exposição. Para pacientes com suspeita ou confirmação de COVID-19 em que o exame ou procedimento seja necessário, os fluxos e as rotas de atendimento, bem como as áreas de espera correspondentes, devem ser separados das vias normais do paciente sem suspeita de infecção por SARS-CoV-2.

- Redução do fluxo de pessoal e da exposição da equipe (profissionais administrativos da recepção, profissionais de higiene, profissionais de saúde).

Finalmente, para hierarquização dos fluxos de atendimento nas diversas áreas da assistência médica em cardiologia, é necessário definir o perfil clínico do paciente, a proximidade física do paciente com a equipe de saúde e o tipo de contato durante o atendimento, além do nível de urgência para o tratamento da doença cardíaca.

O momento da reintrodução do atendimento em cardiologia deve estar alinhado com as políticas institucionais e seguir as recomendações das autoridades competentes. Considerações importantes incluem a incidência local de 
pacientes com infecção por SARS-CoV-2 e a tendência do número de casos, bem como recursos institucionais disponíveis, incluindo instalações, recursos humanos e cadeias de suprimento de EPI. Por exemplo, pode ser necessária a suspensão temporária de atendimentos eletivos se o estoque de EPI estiver limitado, a fim de evitar o desabastecimento do atendimento de urgência e emergência.

À medida que as regiões do país caminhem para situação de controle da epidemia de COVID-19 após o impacto transformador imposto aos serviços de saúde, tais orientações poderão sofrer flexibilização regionalizada. Além disso, o acompanhamento de casos de pacientes e prestadores de serviço é crucial para a identificação da progressão de possível transmissão local e necessidade de aumento do nível de resposta dentro de instituições médicas, particularmente as que possuem leitos de internação. Portanto, é essencial que a comunidade médica permaneça vigilante e atenta ao caráter dinâmico das recomendações tanto na esfera estadual ou municipal como até mesmo dentro de seu consultório, clínica ou instituição hospitalar.

\section{Perfis do Atendimento, Clínico do}

\section{Paciente e do Ambiente de Atendimento}

a. Orientações Gerais Aplicáveis a Todos os Ambientes de Atendimento

Para obter êxito na retomada das atividades, é essencial que todo serviço de atendimento médico defina um plano local elaborado com participação ativa dos membros da equipe médica, dos profissionais com experiência no controle de infecções e segurança do paciente e de demais profissionais de saúde envolvidos na prática assistencial. Assim, destacamos um plano de medidas iniciais aplicável a todos os níveis de atendimento.
- Iniciar o retorno às atividades com capacidade reduzida, por exemplo algo próximo de $25 \%$ da capacidade máxima pré-pandemia, permitindo a implementação controlada das intervenções e a avaliação do fluxo de atendimento. Após constatação de que o fluxo ocorre de forma adequada, podese realizar o aumento escalonado no volume de atendimentos. No entanto, não há expectativa de que o fluxo atinja volumes pré-pandemia durante o período de flexibilização em razão das adaptações necessárias. Deve-se considerar esse aspecto dentro do potencial impacto na sustentabilidade financeira do serviço de saúde.

- Devem-se priorizar os pacientes mais sintomáticos e com doenças de maior probabilidade de descompensação nas próximas semanas ou meses, reduzindo a chance de internações e de complicações a curto e médio prazo e auxiliando no combate à sobrecarga do sistema de internação hospitalar.

- Adequar estrutura física, com o objetivo de garantir distanciamento físico, como demarcações sinalizadas no chão, associadas à utilização de barreiras físicas no ambiente, como painéis de acrílico ou vidro.

- Garantir que os suprimentos de higiene e limpeza, tais como álcool gel, lenços de papel e sabonete para as mãos, estejam prontamente disponíveis e facilmente acessíveis, além de assegurar o descarte adequado de resíduos.

- Elaborar lembretes visuais, como cartazes, placas e posters, que devem ser disponibilizados para os pacientes tanto por via digital quanto afixados na entrada do serviço e em locais estratégicos com informações principais sobre higienização das mãos, etiqueta da tosse e principais sinais e sintomas da COVID-19.

- Manter toda a equipe com uso contínuo de EPI adequado durante todo o tempo de atendimento (Figura 1).

\begin{tabular}{|l|c|c|c|}
\hline \multicolumn{1}{|c|}{} & NÍVEL 1 & NÍVEL 2 & NÍVEL 3 \\
\hline Máscara Cirúrgica & $\checkmark$ & $\checkmark$ & \\
\hline Óculos de proteção & & $\checkmark$ & $\checkmark$ \\
\hline Avental & & $\checkmark$ & $\checkmark$ \\
\hline Luvas & & & $\checkmark$ \\
\hline Máscara N95/PPF2 & & & $\checkmark$ \\
\hline Protetor facial (Face shield) & & & $\checkmark$ \\
\hline Avental impermeável & & & $\checkmark$ \\
\hline Gorro ou touca & & & $\checkmark$ \\
\hline
\end{tabular}

Figura 1 - Orientações de EPI de acordo com os níveis de risco. Para o Nivel 2, os óculos de proteção podem ser substituídos por protetor facial. No Nivel 3, o protetor facial é obrigatório e não pode ser substituído por óculos de proteção. Fonte adaptada: GVIMS/GGTES/ANVISA. 
- Certificar-se de que todos os pacientes e acompanhantes com mais de 2 anos estejam com o rosto coberto com máscara e, para aqueles que não estejam, oferecer máscaras faciais no momento da triagem. É importante ressaltar que alguns locais de atendimento de saúde com características próprias, como hospitais, podem ter regulamentação específica que torne obrigatório o uso de máscaras cirúrgicas descartáveis. Essas especificações devem ser consideradas pelos serviços de assistência na definição de qual máscara exigir do paciente durante o atendimento.

- Para serviços médicos de maior porte com equipe de funcionários maior, deve-se definir um comitê de retomada para discussão continuada de ajustes nas intervenções e no volume de atendimento a fim de reduzir o risco de transmissão.

- No dia anterior à consulta, aplicar o Questionário de Sintomas e Exposição (Suplemento A) por meio eletrônico ou contato telefônico. Todo paciente deve preencher o questionário de sintomas por telefone (verbal) ou por via eletrônica ou impressa.

- Aferir a temperatura corporal de todos os pacientes na chegada para o atendimento.

- Caso seja necessária a realização de consulta ou exame em paciente com suspeita ou confirmação de COVID-19, deve-se reservar uma sala separada para o atendimento.

- No ambiente hospitalar, gerenciar mecanismos de barreira para os pacientes ambulatoriais, criando entradas e saídas "limpas", ou seja, sem contato com os pacientes internados.

- Nos atendimentos de urgência e emergência (definição na seção 2 b), onde não é possível realizar triagem prévia nem adiar o atendimento, aplicar de forma objetiva, após avaliação cardiológica padrão, o Questionário de Sintomas e Exposição para definir o status epidemiológico.

Em caso de qualquer resposta positiva ao questionário (Suplemento A):

- Assegurar que o paciente esteja usando máscara cirúrgica.

- Manter o paciente em uma sala de espera separada, com portas fechadas e, se possível, sinalizada.

- Manter distanciamento físico de 2,0 m.

- O supervisor responsável e o prestador do tratamento médico devem ser comunicados e o atendimento deve ser realizado com a utilização de $\mathrm{EPI}$ adequado por todos os membros da equipe.

- Serviços que ofereçam atendimento de urgência e emergência devem definir fluxo de atendimento específico de acordo com a estrutura local disponível.

\section{b. Definição do Perfil de Atendimento Cardiológico Quanto à sua Urgência}

Para definição do protocolo de atendimento, é necessário considerar a condição clínica e a urgência do paciente atendido. Definimos aqui quatros perfis de atendimento de acordo com as características clínicas do paciente e risco de piora por adiamento do cuidado:
- Perfil A: Situação de atendimento de emergência: quando o atendimento, a avaliação e a intervenção devem ser realizados nos próximos minutos ou horas.

- Perfil B: Situação de atendimento de urgência: quando o atendimento, a avaliação e a intervenção devem ser realizados nos próximos dias.

- Perfil C: Situação de atendimento semi-eletivo: quando o atendimento, a avaliação e a intervenção devem ser realizados nas próximas semanas, idealmente antes de 3 meses.

- Perfil D: Situação de atendimento eletivo: quando não há necessidade de atendimento, avaliação e intervenção a curto prazo, podendo ser postergados para além de 3 meses.

A Tabela 1 detalha as principais apresentações de doenças cardiovasculares de acordo com a classificação acima.

\section{c. Definição do Perfil Clínico do Paciente (Status para COVID-19)}

A apresentação clínica compatível com COVID-19 suspeita ou confirmada deve considerar a definição de SG e de SRAG conforme detalhado na Tabela 2.

O critério clínico, entretanto, não permite estabelecer a etiologia, devendo outros agentes entrar no diagnóstico diferencial, conforme evidências epidemiológicas, dos exames laboratoriais e dos achados radiológicos.

Com relação à infecção por SARS-CoV-2, o perfil clínico de um paciente pode ser classificado como:

- Com suspeita de COVID-19: caso suspeito de SG ou SRAG por critério clínico, radiológico ou laboratorial presuntivo.

- Com confirmação de COVID-19 ativa: caso suspeito de SG ou SRAG com infecção pelo SARS-CoV-2 confirmada por método laboratorial definitivo (RT-PCR para SARS-CoV-2 detectado) ou sorologia IgM E:

- Menos de 10 dias da data de início dos sintomas ou da data do exame, se assintomático; OU

- Menos de 3 dias do último sintoma relacionado à COVID-19.

- Com confirmação de COVID-19 curada: COVID-19 confirmada com evidências de melhora do quadro clínico, definida por ausência de febre por $>3$ dias e melhora dos sintomas respiratórios (tosse, falta de ar) E:

- Pelo menos de 10 dias decorridos desde os primeiros sintomas; OU

- Sorologia IgG reagente com história clínica compatível com COVID-19 prévia.

- Contato de caso suspeito ou confirmado: aquele que esteve em contato (no trabalho, domicílio) há menos de 14 dias com indivíduo classificado em um dos três status acima.

- Assintomático sem contato recente com caso: aquele que não apresenta nenhum sintoma sugestivo de infecção por SARS-CoV-2 nos últimos 10 dias nem contato com caso suspeito ou confirmado nos últimos 14 dias.

- Caso descartado: Caso suspeito de SG ou SRAG sem confirmação da infecção pelo SARS-CoV-2 por método laboratorial definitivo (RT-PCR para SARS-CoV-2 detectado) 
Tabela 1 - Principais apresentações clínicas de doenças cardiovasculares de acordo com a situação de urgência do atendimento

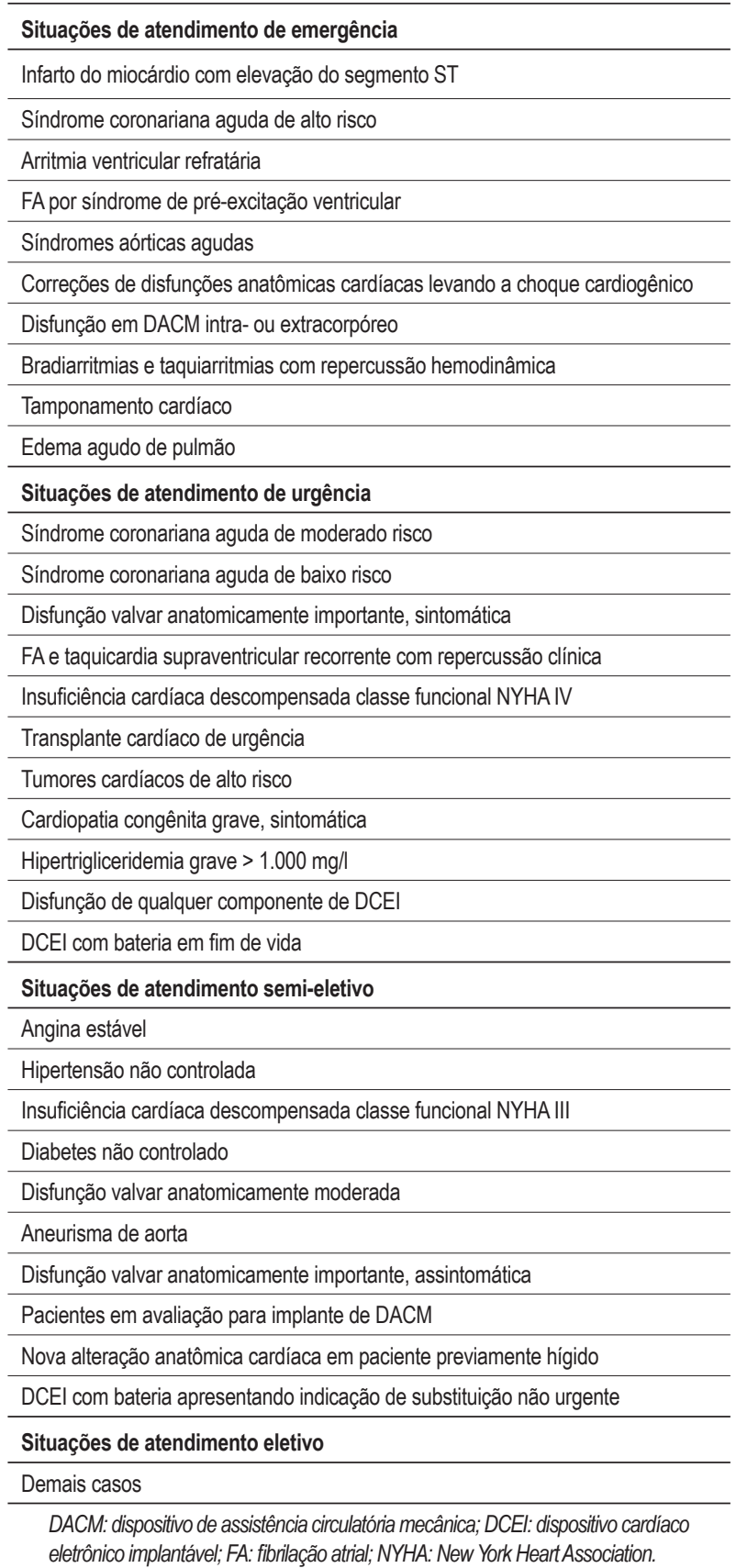

Tabela 2 - Definição de síndrome gripal e síndrome respiratória aguda grave

\begin{tabular}{lc}
\hline Classificação & Características clínicas \\
\hline Síndrome gripal & $\begin{array}{c}\text { Sintomas respiratórios, como tosse, coriza, dor } \\
\text { de garganta, com ou sem febre* }\end{array}$ \\
\hline $\begin{array}{l}\text { Síndrome Respiratória } \\
\text { Aguda Grave }\end{array}$ & $\begin{array}{c}\text { Saturação de } \mathrm{O}_{2}<95 \% \text { em ar ambiente E/OU } \\
\text { frequência respiratória } \geq 24 \text { ipm }\end{array}$ \\
\hline${ }^{*}$ Febre pode não estar presente em alguns casos, como idosos e \\
imunodeprimidos. Nessas situações, a avaliação clínica deve ser \\
levada em consideração.
\end{tabular}

durante a janela de oportunidade de diagnóstico $\mathbf{O U}$ confirmação laboratorial para outro agente etiológico, como vírus influenza ou vírus sincicial respiratório. Em casos de alta suspeição, pode ser necessário repetir o teste de RT-PCR em 48 horas em razão de sua sensibilidade limitada.

\section{d. Definição do Ambiente de Atendimento}

O perfil clínico descrito acima é útil não somente para definir a urgência da realização do atendimento médico, mas também seu modelo estrutural de abordagem. Sempre que possível, o risco de exposição da equipe de saúde e do paciente e seus acompanhantes deve ser minimizado, priorizando-se o atendimento mais seguro, porém efetivo. Para isso, o ambiente de atendimento foi classificado de acordo com a distância e o tempo de contato entre o paciente e a equipe de saúde:

- Ambiente I: Atendimento remoto, onde não há qualquer contato físico entre o paciente e a equipe.

- Ambiente II: Ambiente de contato moderado, onde há contato presencial entre paciente e equipe, com curto tempo de exposição $(<15$ minutos) e/ou maior distanciamento físico $(>1,5 \mathrm{~m})$.

- Ambiente III: Ambiente de contato próximo, há contato físico entre paciente e equipe próximo ou prolongado (> 15 minutos, em ambiente fechado).

- Ambiente IV: Contato invasivo e manipulação potencial de vias aéreas, há contato direto com o paciente ou manipulação de vias aéreas do paciente e exposição a aerossóis.

Para tornar mais objetivo, exemplos de diversos perfis de ambiente para atendimentos cardiológicos de rotina encontram-se detalhados na Tabela 3. É importante enfatizar o estímulo à emissão de laudos/diagnósticos, sempre que possível, via acesso remoto.

\section{Medidas de Precaução e Isolamento COVID-19}

O risco ocupacional de exposição ao SARS-CoV-2 pode ser dividido em quatro níveis: muito alto, alto, médio e baixo risco (Figura 2). A avaliação do risco ocupacional depende da distância e do tempo de contato entre o profissional e o paciente, do tipo de procedimento realizado e do seu risco de geração de aerossóis, além do perfil clínico do paciente com relação à infecção pelo SARS-CoV-2.

Dessa forma, além das precauções-padrão, as seguintes devem ser implementadas pelos serviços de saúde:

- Precauções contra contato.

- Precauções contra gotículas.

- Precauções contra aerossóis.

Alguns procedimentos que podem gerar aerossóis são: entubação ou aspiração traqueal, ventilação mecânica não invasiva, ressuscitação cardiopulmonar, ventilação manual antes da entubação, coleta de amostras nasotraqueais, broncoscopia. Para os atendimentos em que esses procedimentos são rotineiros ou potencialmente necessários, as precauções contra gotículas devem ser substituídas pelas precauções contra aerossóis. 


\section{Posicionamento}

Tabela 3 - Classificação dos ambientes de atendimento cardiológico de acordo com o contato interpessoal

\begin{tabular}{l}
\hline Ambientes de trabalho da equipe de cardiologia \\
\hline Atendimento remoto \\
\hline Sistemas de suporte à decisão \\
\hline Teleconsultoria, incluindo orientação telefônica \\
\hline Telerregulação \\
\hline Telediagnóstico e laudos à distância \\
\hline Teleducação \\
\hline Ambiente de contato moderado \\
\hline Estacionamento (serviço de manobrista) \\
\hline Profissionais da recepção e equipe administrativo em geral \\
\hline Profissionais de segurança \\
\hline Ambiente de contato próximo \\
\hline Consultas médicas presenciais \\
\hline Equipe presencial em exames de medicina nuclear \\
\hline Equipe presencial em exames de imagem (tomografia computadorizada, \\
ressonância magnética, ecocardiograma) \\
\hline Equipe presencial em métodos gráficos em cardiologia \\
\hline Contato invasivo e manipulação potencial de vias áreas \\
\hline Oroscopia em exame físico, teste de esforço \\
\hline Ecocardiograma transesofágico \\
\hline Procedimentos invasivos em eletrofisiologia \\
\hline Procedimentos invasivos em cardiologia intervencionista \\
\hline
\end{tabular}

Portanto, os EPI necessários para o atendimento de casos suspeitos ou confirmados consistem em:

\section{a. Medidas de Precaução-Padrão}

Instituídas para todos os pacientes e englobam:

- Higienização das mãos.

- Uso de máscara - durante a vigência da epidemia conforme detalhado abaixo para o nível 1 de EPI.

Se houver risco de exposição a sangue ou secreções:

- Uso de luvas de procedimento.

- Uso de óculos de proteção e avental.

Compreendem também o descarte adequado.

\section{b. Medidas de Precaução contra Contato + Gotículas}

- Máscara cirúrgica.

- Óculos de proteção ou protetor facial (face shield).

- Avental com gramatura mínima de $30 \mathrm{~g} / \mathrm{m}^{2}$.

- Luvas de procedimentos.

c. Medidas de Precaução contra Contato + Aerossóis

- Máscara N95/PPF2 ou equivalente.

- Protetor facial (face shield).

- Avental impermeável.

- Gorro.

- Luvas de procedimentos.

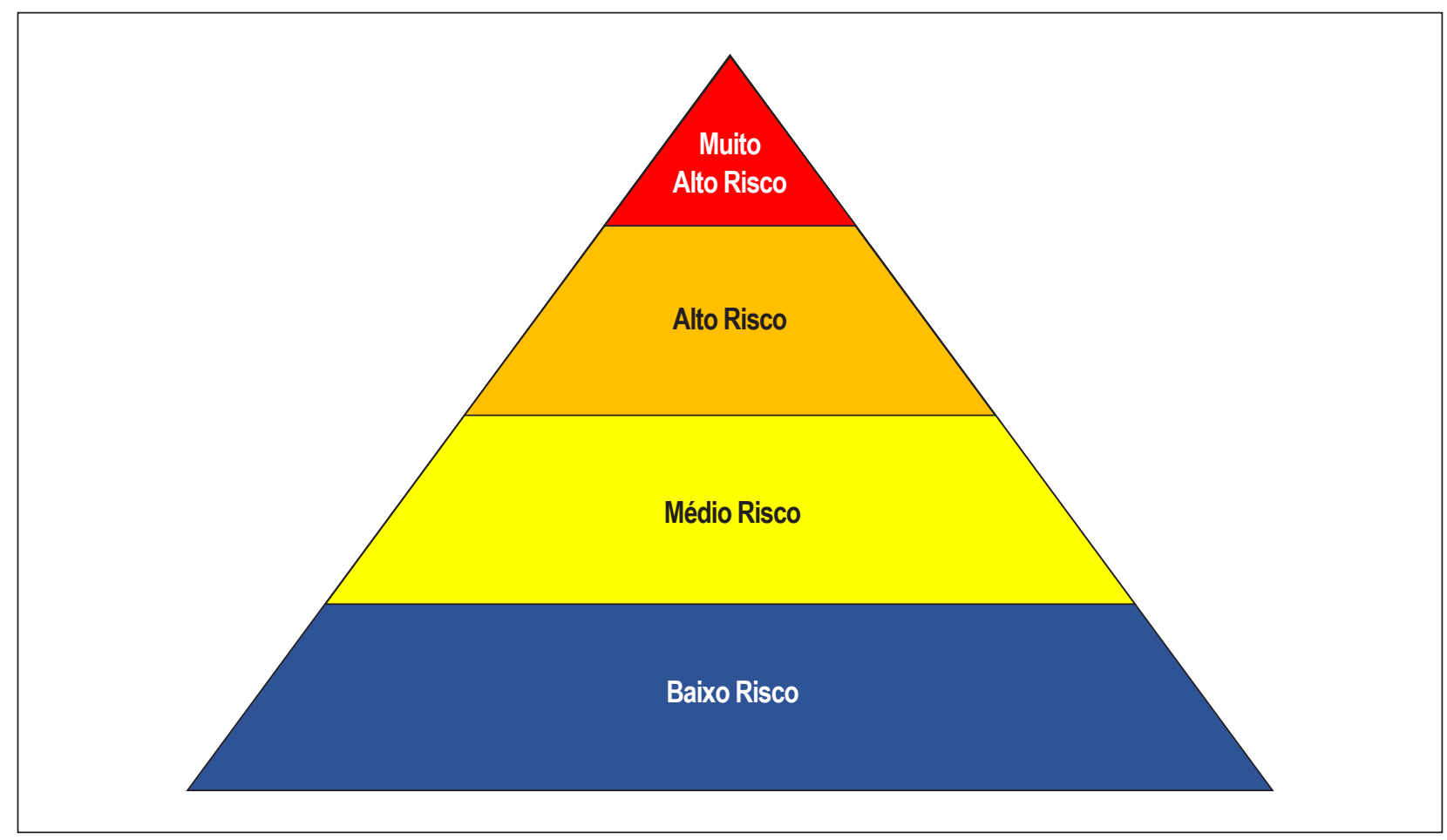

Figura 2 - Pirâmide de risco ocupacional para COVID-19 (adaptada de Occupational Safety and Health Administration - OSHA). ${ }^{14}$ 
Além dos procedimentos geradores de aerossóis, quando o paciente estiver com expectoração abundante, sangramento, vômitos ou diarreia, o profissional de saúde deve usar avental impermeável. O uso racional do EPI nos serviços de saúde é necessário e, por ser o EPI considerado um recurso finito, pode haver alteração nas recomendações de sua utilização em razão de planos de contingência durante a pandemia.

d. Recomendação de EPI de Acordo com a Complexidade dos Procedimentos e o Perfil Clínico do Paciente Figuras 1 e 2, Tabela 4)

Nível 1 de EPI: Para médio risco, ambiente de contato moderado.

\section{Medidas de Precaução-Padrão}

Indicadas para procedimentos NÃO invasivos quando realizados em caráter eletivo $\mathrm{E}$ em pacientes sem suspeita de COVID-19.

- Profissionais responsáveis por atividades que não envolvam contato a menos de 2,0 m com os pacientes poderão utilizar máscara de tecido.

- Se não for garantido o distanciamento de 2,0 m do paciente, deve-se utilizar máscara cirúrgica durante as atividades (Tabela 5).

- Instituir barreiras físicas, de forma a favorecer o distanciamento maior que 2,0 m, por exemplo, placas de acrílico e faixas no piso (Tabela 5).

Nível 2 de EPI: Para alto risco, ambiente de contato próximo.

\section{Medidas de Precaução contra Contato + Gotículas}

Indicadas para procedimentos NÃO invasivos em caráter de emergência OU em pacientes com confirmação OU suspeita de infecção por SARS-CoV-2.
Nível 3 de EPI: Para muito alto risco, contato invasivo de vias aéreas.

\section{Medidas de Precaução contra Contato + Aerossóis}

Indicadas para procedimentos invasivos e potencialmente geradores de aerossóis quando realizados:

- em caráter eletivo $\mathrm{E}$ em pacientes sem suspeita de COVID-19.

- em caráter de emergência OU em pacientes com confirmação OU suspeita de infecção por SARS-CoV-2.

Nota: Em procedimentos invasivos, substituir os EPI (luvas, aventais) por equipamento devidamente esterilizado.

Importante destacar que a máscara de tecido não é um EPI, por isso não deve ser usada por profissionais de saúde ou de apoio em situações em que haja indicação de uso de máscara cirúrgica (durante a assistência ou contato direto, a menos de 2,0 m de pacientes) ou de máscara N95/PFF2 (durante a realização de procedimentos potencialmente geradores de aerossóis).

\section{e. Limpeza e Desinfecção de Superfícies}

Não há recomendação diferenciada para a limpeza e a desinfecção de superfícies após o contato com casos suspeitos ou confirmados de COVID-19. Porém, é fundamental que os serviços revisem os procedimentos operacionais de limpeza e desinfecção de ambientes e superfícies para garantir melhores práticas e aumento da periodicidade de limpeza. ${ }^{14,15,16}$

- Com relação aos equipamentos específicos no manejo cardiológico, todos deverão ser limpos a cada término de jornada de trabalho, ainda com os profissionais usando EPI e evitando contato com os materiais infectados.

- Monitores e superfícies de máquina de ultrassom poderão ser cobertos com filme plástico para diminuir risco de contaminação e facilitar a limpeza.

Tabela 4 - Definição do nível de EPI a ser utilizado de acordo com o risco apresentado

\begin{tabular}{|c|c|c|c|}
\hline Risco & Tipo de exposição & Tipo de atendimento & Nível de EPI \\
\hline $\begin{array}{l}\text { Muito alto risco } \\
\text { Contato invasivo de vias aéreas }\end{array}$ & $\begin{array}{c}\text { Exposição a pacientes com confirmação ou } \\
\text { suspeita de COVID-19 } \\
\text { Procedimentos que geram aerossóis }\end{array}$ & $\begin{array}{c}\text { Oroscopia e oftalmoscopia } \\
\text { ETE, teste de esforço } \\
\text { Procedimentos invasivos em eletrofisiologia e em } \\
\text { cardiologia intervencionista }\end{array}$ & Nível 3 \\
\hline $\begin{array}{l}\text { Alto risco } \\
\text { Ambiente de contato próximo }\end{array}$ & $\begin{array}{l}\text { Exposição a pacientes com confirmação ou } \\
\text { suspeita de COVID-19 }\end{array}$ & $\begin{array}{l}\text { Exames de medicina nuclear } \\
\text { Exames de imagem (TC, RM, ETT) } \\
\text { Métodos gráficos em cardiologia }\end{array}$ & Nível 2 \\
\hline $\begin{array}{l}\text { Médio risco } \\
\text { Ambiente de contato moderado }\end{array}$ & Contato frequente e próximo & $\begin{array}{l}\text { Profissionais da recepção } \\
\text { Staff administrativo em geral } \\
\text { Estacionamento } \\
\text { Consultas presenciais }\end{array}$ & Nível 1 \\
\hline $\begin{array}{l}\text { Baixo risco } \\
\text { Atendimento remoto }\end{array}$ & Sem contato com pacientes & $\begin{array}{l}\text { Telerregulação } \\
\text { Telediagnóstico } \\
\text { Teleducação }\end{array}$ & Sem EPI específicc \\
\hline
\end{tabular}

ETE: ecocardiograma transesofágico; ETT: ecocardiograma transtorácico; RM: ressonância magnética; TC: tomografia computadorizada. Para pacientes com suspeita ou confirmação de COVID-19, as consultas presenciais devem ser realizadas com EPI nível 2. Algumas diretrizes consideram que exames de imagem e métodos gráficos, exceto teste ergométrico, podem ser realizados somente com máscara cirúrgica, particularmente quando há baixa probabilidade de COVID-19 ativa, como quando o caso é de paciente com COVID-19 curada ou em casos sem sintomas ou contato recente e exame negativo para COVID-19 recente. 
Tabela 5 - Precauções-padrão de acordo com o distanciamento

\begin{tabular}{ll}
\hline Tipo de precaução & Padrão \\
\hline Profissionais $>2,0 \mathrm{~m}$ do paciente & Máscara de tecido \\
Profissionais $<2,0 \mathrm{~m}$ do paciente & Máscara cirúrgica \\
\hline
\end{tabular}

A máscara de tecido não deve ser utilizada pela equipe de saúde no atendimento.

- Após a saída do paciente com suspeita ou confirmação, realizar a limpeza/desinfecção, com saneante de uso habitual, dos equipamentos e de todas as áreas que entraram em contato com o paciente, além das áreas tocadas pelos profissionais de saúde durante o atendimento.

\section{Estratégia de Abordagem no Contexto do Ambiente de Atendimento}

\section{a. Ambiente de Atendimento Presencial}

Classificação: Ambiente II (contato moderado)

Risco: Baixo a moderado

Os ambientes de atendimento presencial são aqueles onde os serviços de saúde são prestados no âmbito extra-hospitalar. Incluem unidades básicas de saúde, ambulatórios médicos de especialidades, ambulatórios hospitalares, clínicas e consultórios médicos. São parte essencial na resposta do sistema de saúde, já que há um potencial aumento de desfechos cardiovasculares a médio prazo em razão do déficit na assistência médica a essa população. As adaptações do protocolo de atendimento devem incluir as seguintes modificações na rotina: ${ }^{16}$

\section{Agendamento}

- A marcação de consultas deve ser realizada prioritariamente por meios não presenciais (telefônico ou on-line), em plataformas dedicadas ou via aplicativos de mensagens.

- Os agendamentos devem iniciar com horários espaçados e intervalos entre os atendimentos, permitindo que um paciente deixe o ambiente, incluindo a sala de espera, antes da chegada do próximo atendimento, minimizando o contato entre pacientes.

- A triagem de pacientes com sintomas respiratórios deve ser realizada no agendamento e na confirmação da consulta, utilizando questionário (Suplemento A).

- Deve-se orientar e exigir o uso de máscara pelo paciente e acompanhante independentemente da presença de sintomas ou das respostas ao questionário.

- Deve-se orientar quanto ao comparecimento ao atendimento sem acompanhante, sempre que possível. Quando estritamente necessário, indicar a aceitação de apenas um acompanhante, que também deve responder ao mesmo questionário de sintomas.

\section{Estrutura Física/ Sala de Espera}

- Manter os ambientes ventilados (ar condicionado com exaustão, que garanta as trocas de ar, ou manter as janelas abertas).
- Reduzir o número de pessoas da equipe da recepção que terá contato físico com o paciente.

- Utilizar barreiras físicas na recepção para reduzir contato, como placas de acrílico e demarcações no chão para distanciamento físico de no mínimo 2,0 m.

- Adicionar alertas visuais nas entradas e em locais estratégicos com instruções sobre higiene das mãos, etiqueta da tosse e sinais e sintomas suspeitos para COVID-19.

- Disponibilizar lenço descartável para higiene nasal ou etiqueta da tosse na sala de espera. Prover lixeira com acionamento por pedal para o descarte de lenços de papel.

- Disponibilizar dispensadores com preparações alcoólicas para a higiene das mãos e lavatório/pia com dispensador de sabonete líquido, suporte para papel toalha, papel toalha, lixeira com tampa e abertura sem contato manual.

- Estimular espera em ambiente aberto ou externo, respeitando o distanciamento físico de 2,0 m.

- Sinalizar distância mínima entre os assentos de 2,0 m.

- Utilizar copos descartáveis para água e café.

- Retirar objetos compartilhados, como revistas e jornais.

- Orientar higienização das mãos antes e após o preenchimento de fichas, o uso de canetas e o pagamento com cartão. Higienizar a máquina de cartão e, para facilitar o processo, a máquina poderá ser envolvida em plástico filme, sempre procedendo à higienização após cada uso.

- Fornecer máscara cirúrgica para pacientes com sintomas respiratórios e orientar o uso correto durante toda a sua permanência na unidade, caso o atendimento seja estritamente necessário. Pacientes com atendimentos eletivos ou semi-eletivos devem ser orientados a retornar ao seu domicílio para isolamento individual e investigação de COVID-19, com reagendamento para atendimento posterior. As máscaras devem ser trocadas sempre que estiverem sujas ou úmidas.

- Caso o paciente apresente sintomas respiratórios, encaminhá-lo para uma sala de isolamento ou área separada, isolada dos demais pacientes.

- Aumentar a frequência de limpeza e desinfecção do ambiente, objetos e superfícies mais tocados.

- Não há recomendação do uso de tapetes com soluções saneantes na entrada do serviço ou cabines de desinfecção, pois não têm eficácia documentada.

- Nenhum tipo de produto deve ser borrifado nos pacientes, acompanhantes ou equipe assistencial, pelo alto risco de intoxicação e falta de evidência científica para uso. 


\section{Acompanhante}

Recomendar que os pacientes compareçam sem acompanhantes.

- Caso identificada a necessidade de acompanhante para paciente com autocuidado limitado ou por outra razão, permitir presença de apenas uma pessoa não pertencente ao grupo de risco (Tabela 6).

- No dia anterior à consulta, aplicar o Questionário de Sintomas e Exposição também ao acompanhante.

- Não se recomenda a realização de consultas de pacientes que necessitem de atendimento eletivo ou semi-eletivo e que tenham acompanhantes sintomáticos ou com contato recente com casos suspeitos ou confirmados de COVID-19.

- Os acompanhantes devem seguir todas as orientações e recomendações fornecidas aos pacientes.

\section{b. Atendimento Via Telemedicina}

Classificação: Ambiente I (remoto)

Risco: Nenhum

O atendimento via telemedicina é peça fundamental no retorno racional às atividades e foi pormenorizado na Diretriz da Sociedade Brasileira de Cardiologia sobre Telemedicina na Cardiologia 2019.17 No contexto dessa diretriz, devemos enfatizar o conceito de teleconsulta e telemonitoramento e destacar que seu uso é recomendado, exceto em casos de urgência e emergência, onde o atendimento presencial é necessário. Além da recomendação geral para seu uso, vale salientar que o atendimento à distância deve ser preferido também quando o prestador de serviços de saúde é do grupo de risco.

- Todas as consultas médicas por telemedicina devem obrigatoriamente ocorrer via teleatendimento com sincronia de áudio e vídeo, além de equipamentos que garantam o sigilo médico do atendimento e o registro adequado da consulta em prontuário.

- A telemedicina pode ser utilizada rotineiramente para a realização de pré-consulta pelo médico, que deve avaliar a necessidade de o paciente comparecer presencialmente, definir o risco do quadro clínico, encaminhar para hospital ou mesmo resolver o caso com atendimento completo por telemedicina.

- O atendimento remoto deve ser feito preferencialmente com ferramentas de certificação digital e assinatura eletrônica, configurando originalidade das informações, bem como segurança para o médico e o paciente.

\section{c. Acompanhamento Remoto}

\section{Classificação: Ambiente I (remoto)}

\section{Risco: Nenhum}

O telemonitoramento de sinais vitais necessários e de resultados de exames pode ocorrer por outros meios de acesso remoto. São exemplos de telemonitoramento: seguimento de sintomas na insuficiência cardíaca, níveis pressóricos, telemetria de dispositivo cardíaco eletrônico implantável. Encaixam-se no atendimento de telemonitoramento o controle de exames laboratoriais à distância, como função renal, controle de anticoagulação etc.

O telemonitoramento pode e deve ser utilizado para acompanhamento remoto de pacientes com o objetivo de diminuir o número de consultas presenciais, reduzindo o trânsito e a mobilidade dos pacientes, sempre que possível.

\section{Estratégia de Abordagem no Contexto dos Exames Não Invasivos}

\section{a. Métodos Gráficos em Cardiologia}

Os exames complementares que compreendem os métodos gráficos, de acordo com a proximidade entre paciente e profissional, podem ser classificados com relação ao ambiente da seguinte forma:

\section{Atendimento Remoto/ à Distância \\ - Monitorização Residencial da Pressão Arterial (MRPA). \\ Ambiente de Contato Moderado \\ - Eletrocardiografia de repouso. \\ - Holter. \\ - Monitorização Ambulatorial da Pressão Arterial (MAPA).}

\section{Ambiente de Contato Próximo}

- Teste da inclinação (Tilt-table test).

Assim como orientado para as demais áreas da cardiologia, deve-se realizar o agendamento, por vias não presenciais, em horários programados para reduzir o número de pessoas ao mesmo tempo na sala de espera. O Questionário de Sintomas e Exposição deve ser aplicado no dia anterior ao procedimento, tanto para o paciente quanto para o acompanhante. Esse último deve estar presente apenas se imprescindível ao atendimento e não deve pertencer ao grupo de risco para infecção por SARS-CoV-2 (Tabela 6).

No contexto específico dos métodos gráficos, devem-se estimular os meios não presenciais de diagnóstico, como o acesso remoto e o telediagnóstico em tempo real, ferramentas que reduzem tanto o número de profissionais de saúde expostos como o seu tempo de contato com o paciente. Em casos em que esses exames não podem ser postergados, a orientação para a reabertura inclui:

- Emitir laudo por meio não presencial de eletrocardiograma, Holter, MAPA, MRPA.

- Dar prioridade ao uso da MRPA no lugar do MAPA, quando possível.

- Seguir os protocolos institucionais de contato e higienização/limpeza para instalação e devolução dos aparelhos de Holter e MAPA.

- Considerar outro método alternativo ao teste ergométrico para avaliar isquemia miocárdica, com associação de técnicas de imagem ao estresse farmacológico para reduzir a exposição da equipe a gotículas e aerossóis. 


\begin{tabular}{l} 
Tabela 6 - Avaliação de grupo de risco para triagem dos acompanhantes \\
\hline Idade $>65$ anos \\
\hline Obesidade \\
\hline Hipertensão arterial sistêmica \\
\hline Diabetes mellitus \\
\hline Tabagismo \\
\hline Insuficiência cardiaca \\
\hline Doença pulmonar obstrutiva crônica \\
\hline Doença renal crônica \\
\hline Anemia falciforme \\
\hline Estados de imunossupressão contínua (transplantes, infecção pelo HIV, doença \\
oncológica, uso crônico de imunossupressores) \\
\hline Asma (moderada a grave) \\
\hline Doença cerebrovascular \\
\hline Gravidez \\
\hline Doença hepática \\
\hline
\end{tabular}

\section{b. Teste de Esforço}

\begin{tabular}{l}
\hline Classificação: Contato invasivo de vias aéreas \\
\hline Risco: Muito alto risco \\
\hline
\end{tabular}

É ferramenta importante, visto sua ampla utilização, sendo o principal método de avaliação de isquemia em diversos serviços no país. No entanto, deve-se ter cautela durante o período de transmissão comunitária sustentada, pois há maior risco de transmissão pelo aumento da frequência respiratória durante o teste, aumento da emissão de gotículas, ambiente fechado e longo tempo de permanência em sala. Portanto, exames eletivos e semi-eletivos devem ser avaliados caso a caso. Recomenda-se considerar o adiamento desse teste durante a fase de maior transmissão comunitária do SARS-CoV-2.

Ainda, nos casos raros em que o exame possa ser considerado necessário em pacientes com suspeita ou confirmação de infecção por SARS-CoV-2 recente, realizá-lo observando-se as precauções específicas, Nível 3 (precaução contato + aerossóis). Devido ao fato de as evidências científicas ainda serem incertas com relação a esse tipo de exposição, há a possibilidade de mudança na recomendação em futuras publicações.

Com relação ao teste de inclinação, embora haja exposição prolongada do profissional de saúde, não há aumento de trabalho respiratório, podendo-se inferir que o risco de transmissão não é tão aumentando. Assim, orienta-se precaução Nível 2.

- No caso de realização de teste ergométrico, o paciente deve permanecer com máscara cirúrgica durante toda a duração do exame. ${ }^{18}$

- Não se recomenda a presença de outras pessoas (familiares, pais, treinadores etc.) na sala de ergometria.

- Devem-se priorizar manguitos automáticos de pressão arterial sempre que disponíveis.

- As equipes de saúde devem utilizar os EPI preconizados conforme a proximidade com o paciente, precaução específica de nível 3.
- As equipes de saúde devem realizar o exame mantendo o maior distanciamento físico possível do paciente, que deve ser, no mínimo, de 2,0 m.

- Recomenda-se que a sala de ergometria seja ventilada ativamente, além de intervalo de tempo entre os testes ergométricos individuais idealmente de pelo menos 60 minutos em cada esteira para permitir tempo suficiente para a adequada higienização dos equipamentos.

- Todo o equipamento utilizado para a realização do exame deve ser adequadamente higienizado entre cada paciente avaliado.

\section{c. Ecocardiograma}

A reabertura dos serviços de ecocardiograma deve contemplar as medidas já descritas em relação ao agendamento não presencial, ao maior intervalo entre os agendamentos, às recomendações para acompanhantes, à limpeza e higienização do ambiente e ao distanciamento físico. Em virtude da grande proximidade entre o operador responsável pelo exame e o paciente durante a aquisição das imagens, deve-se considerar o adiamento de exames eletivos e semi-eletivos durante o período de transmissão comunitária sustentada, particularmente para pacientes de grupos de risco (Tabela 7).

\section{d. Ecocardiograma Transtorácico (ETT)}

\section{Classificação: Ambiente de contato próximo}

Risco: Alto Risco

- Na fase inicial da reabertura, agendar primeiro os exames de alta prioridade e, na sequência, os de média prioridade, conforme momento epidemiológico local e sucesso da reabertura.

- Aplicar com antecedência os questionários de sintomas e exposição e repetir a triagem antes dos procedimentos.

- Utilização de EPI adequado pela equipe.

\section{e. Ecocardiograma Transesofágico (ETE)}

\begin{tabular}{l} 
Classificação: Contato invasivo de vias aéreas \\
\hline Risco: Muito Alto Risco
\end{tabular}

As considerações gerais para realização de ETE seguem os mesmos princípios descritos acima. Entretanto, são recomendadas precauções adicionais em virtude do potencial de dispersão de aerossóis relacionada a estímulo do reflexo da tosse em pacientes com via aérea não protegida, recomendando-se a utilização adequada de EPI completo e universal e higienização meticulosa da sala de exames e dos equipamentos.

Idealmente, os procedimentos que podem gerar aerossóis devem ser realizados em uma unidade de isolamento respiratório com pressão negativa e filtro HEPA (High Efficiency Particulate Arrestance). Na ausência desse tipo de unidade, deve-se colocar o paciente em um quarto individual com portas fechadas e restringir o número de profissionais durante esses procedimentos. Em razão do alto risco que o ETE representa, sua indicação deve ser avaliada caso a caso durante a pandemia. 
Tabela 7 - Classificação de prioridade para realização do ecocardiograma

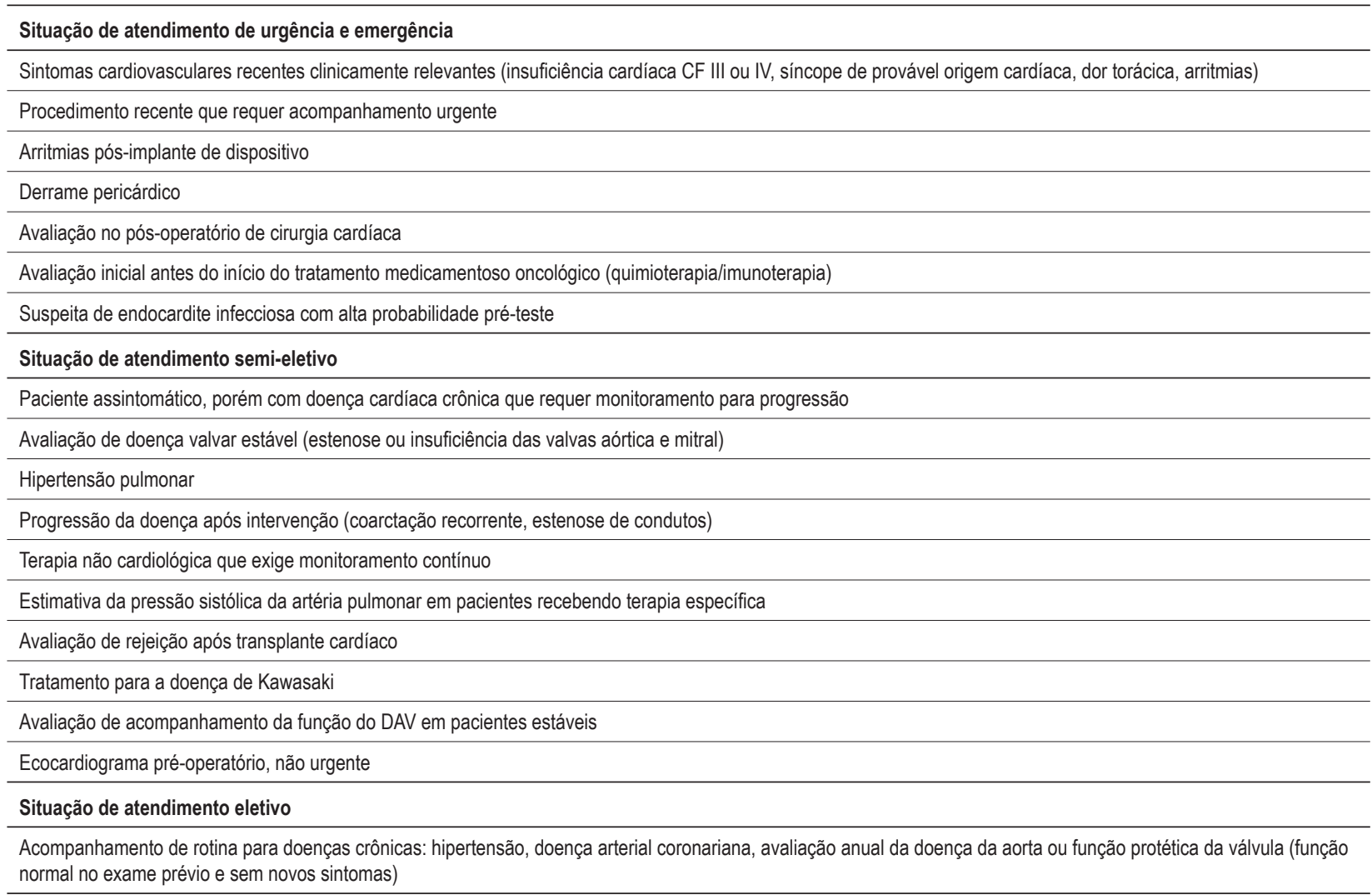

CF: classe funcional; DAV: dispositivo de assistência ventricular.

\section{EPI Recomendados}

Utilização de precaução específica de nível 3 (precaução contra contato + aerossóis) para todos os operadores em contato com a via aérea do paciente e a equipe de apoio que estiver na sala.

\section{Higienização do Equipamento}

O detalhamento da higienização do equipamento de ETE está além do escopo do presente documento. Outros documentos de protocolos de higienização e desinfecção fornecidos pelos serviços de controle de infecção hospitalar e normativas técnicas institucionais devem ser seguidos de forma rotineira.

\section{f. Ecocardiograma de Estresse}

\section{Classificação: Ambiente de contato próximo}

\section{Risco: Alto Risco}

O ecocardiograma realizado com estresse físico promove as mesmas alterações da frequência respiratória descritas para o teste ergométrico, com o agravante de que o operador não pode se distanciar adequadamente do paciente. Por esses motivos, o estresse físico deve ser considerado procedimento de exceção e não ser realizado rotineiramente até o controle adequado da transmissão comunitária da COVID-19. Considera-se alternativa adequada a realização do ecocardiograma de estresse com agentes farmacológicos ou a realização de outros métodos de imagem quando necessário. Em caso de exceção em que o ecocardiograma com estresse físico tenha que ser realizado, recomenda-se a utilização de precaução específica de nível 3 (precaução contra contato + aerossóis) por todos os profissionais presentes no ambiente.

O ecocardiograma de estresse com dobutamina ou outros agentes farmacológicos deve ser a alternativa preferencial durante o período vigente, devendo-se seguir todas as precauções recomendadas para a realização do ecocardiograma de repouso.

\section{Pacientes com COVID-19 Confirmada ou Suspeita}

Os exames de ecocardiograma em pacientes com quadro agudo e diagnóstico de COVID-19 confirmado ou suspeito devem ser realizados apenas em casos de urgência e emergência, nos quais se espera que o resultado do exame tenha real impacto na conduta clínica. Recomenda-se preferencialmente o uso de aparelhos portáteis com atenção especial à proteção da equipe.

- Planejar com antecedência o ecocardiograma para análise apenas das janelas necessárias para a tomada de decisão.

- Utilizar o tempo ao lado do paciente apenas para adquirir as imagens e vídeos, realizando-se posteriormente as medidas em software dedicado.

- Remanejar os profissionais em formação e ecocardiografistas menos experientes para as áreas não COVID-19 no intuito de minimizar o tempo de realização do exame. 
- As equipes de saúde devem utilizar os EPI preconizados conforme a proximidade com o paciente, precaução específica de nível 3 (precaução contato + aerossóis).

\section{g. Tomografia Computadorizada (TC) e Ressonância Magnética (RM) do Coração}

Classificação: Ambiente de contato moderado

\section{Risco: Médio Risco}

Em todo o mundo, os departamentos de radiologia e suas salas de modalidade de imagem não foram projetadas com medidas restritivas de transmissão de doenças infecciosas. Entretanto, os exames de imagem são ferramentas essenciais no diagnóstico e tratamento da COVID-19 e suas complicações.

São obrigatórias as medidas iniciais já descritas para outros exames relacionadas ao agendamento não presencial, ao maior intervalo entre os atendimentos da agenda, às recomendações para acompanhantes, à limpeza/higienização do ambiente e ao distanciamento físico.

No processo de adaptação para o funcionamento sob as atuais condições incomuns, os pacientes com suspeita ou confirmação de COVID-19 devem ser submetidos preferencialmente aos exames em equipamentos dedicados a esse perfil clínico, a fim de evitar a contaminação cruzada entre populações de pacientes infectados e não infectados. Esse aspecto é de particular importância, pois a realização de TC para a investigação de pacientes com suspeita ou quadro confirmado de COVID-19 é frequente. Caso isso não seja possível, é necessário definir, no equipamento disponível, intervalos de tempo dedicados ao perfil clínico "COVID-19 suspeita ou confirmada", de preferência no final do dia. Devido à viabilidade do SARS-CoV-2 em vários tipos de superfícies e condições ambientais, é obrigatória a limpeza da instalação de imagem após cada paciente com COVID-19 suspeita ou confirmada antes da obtenção de imagens de um paciente sem suspeita ou confirmação de COVID-19, devendo a limpeza ser realizada de acordo com os protocolos institucionais.

Deve-se considerar o reagendamento de exames eletivos e semi-eletivos durante o período de transmissão comunitária mais intensa da COVID-19. Exames de urgência e emergência devem ser considerados conforme necessidade clínica e expectativa de definição de conduta de tratamento baseada no resultado dos exames.

Nos casos de pacientes internados, a imagem cardiovascular pode ser usada para substituir exames invasivos ou com manipulação de vias aéreas, como o ETE e a cineangiocoronariografia. Assim, em casos selecionados, pode-se lançar mão da TC cardíaca para pesquisa de trombo em apêndice atrial esquerdo ou angiotomografia de coronárias em síndrome coronariana aguda sem elevação do segmento ST. Para pacientes com perfil clínico A ou $B$, em que o exame seja considerado necessário e não substituível, ou em casos selecionados de pacientes com perfil clínico C em que o exame seja necessário, os protocolos de cuidado de nível 2 devem ser recomendados. Devido ao baixo grau de evidência, esta recomendação é feita por segurança e outras diretrizes podem recomendar somente o uso de máscara cirúrgica em pacientes sem suspeita de COVID-19. Esta estratégia é particularmente aceitável em casos de COVID-19 curada ou em casos sem sintomas e exame negativo recente.
A RM cardíaca, pelo seu tempo prolongado de execução e, consequentemente, maior exposição da equipe, deve ser indicada de forma seletiva em casos suspeitos ou confirmados de COVID-19, como no diagnóstico diferencial entre miocardite, síndrome de Takotsubo e infarto do miocárdio sem lesões coronarianas obstrutivas (MINOCA). As indicações e os níveis de prioridade para TC e RM estão detalhados na Tabela 8.

\section{h. Medicina Nuclear}

\section{Classificação: Ambiente de contato moderado}

\section{Risco: Médio Risco}

Como na seção de ecocardiografia, é importante definir o escalonamento de prioridades dos exames de medicina nuclear, observando-se o perfil clínico do paciente. Exames eletivos e semi-eletivos (perfis C e D) devem ser considerados para reagendamento posterior enquanto a transmissão comunitária da COVID-19 esteja ocorrendo de forma sustentada. Esse aspecto é particularmente importante para pacientes de risco para COVID-19, incluindo idade > 60 anos, hipertensão arterial sistêmica, diabetes, doença pulmonar crônica e demais doenças crônicas, um perfil bastante comum entre aqueles que realizam exames de medicina nuclear. Para pacientes com perfil clínico A ou B, em que o exame seja considerado necessário e não substituível, ou em casos selecionados de pacientes com perfil clínico $\mathrm{C}$ em que o exame seja necessário, os protocolos de cuidado de nível 2 devem ser recomendados. Considerar sempre os riscos descritos para o teste ergométrico, caso o estresse físico seja aventado. Devido ao baixo grau de evidência, esta recomendação é feita por segurança e outras diretrizes podem recomendar somente o uso de máscara cirúrgica em pacientes sem suspeita de COVID-19. Esta estratégia é particularmente aceitável em casos de COVID-19 curado ou em casos sem sintomas e exame negativo recente. Assim, as orientações abaixo buscam alinhar o planejamento com as diretrizes mundiais:

\section{- Com o intuito de abreviar o tempo do exame}

- Selecionar o protocolo com a menor duração de tempo de aquisição;

- Considerar o início do protocolo pela fase de estresse e realização do exame em apenas um dia, principalmente em pacientes com baixa probabilidade de isquemia miocárdica;

- Considerar protocolos restritos à imagem de estresse;

- Considerar agente farmacológico com menor tempo de infusão.

- Com o intuito de reduzir o risco de exposição do profissional de saúde

- Avaliar rigorosamente o critério para o estresse físico com teste ergométrico para, nesse momento, minimizar seu uso, assim priorizando protocolos com estresse farmacológico;

- Considerar uso de manguitos automáticos de pressão arterial quando disponíveis;

- Considerar manter a vigilância por vídeo durante o teste;

- Em protocolos de estresse com adenosina e dipiridamol, extensores podem ser usados para manter o distanciamento entre a equipe e o paciente; 
Tabela 8 - Indicações de tomografia computadorizada / ressonância magnética de coração durante a pandemia por COVID-19

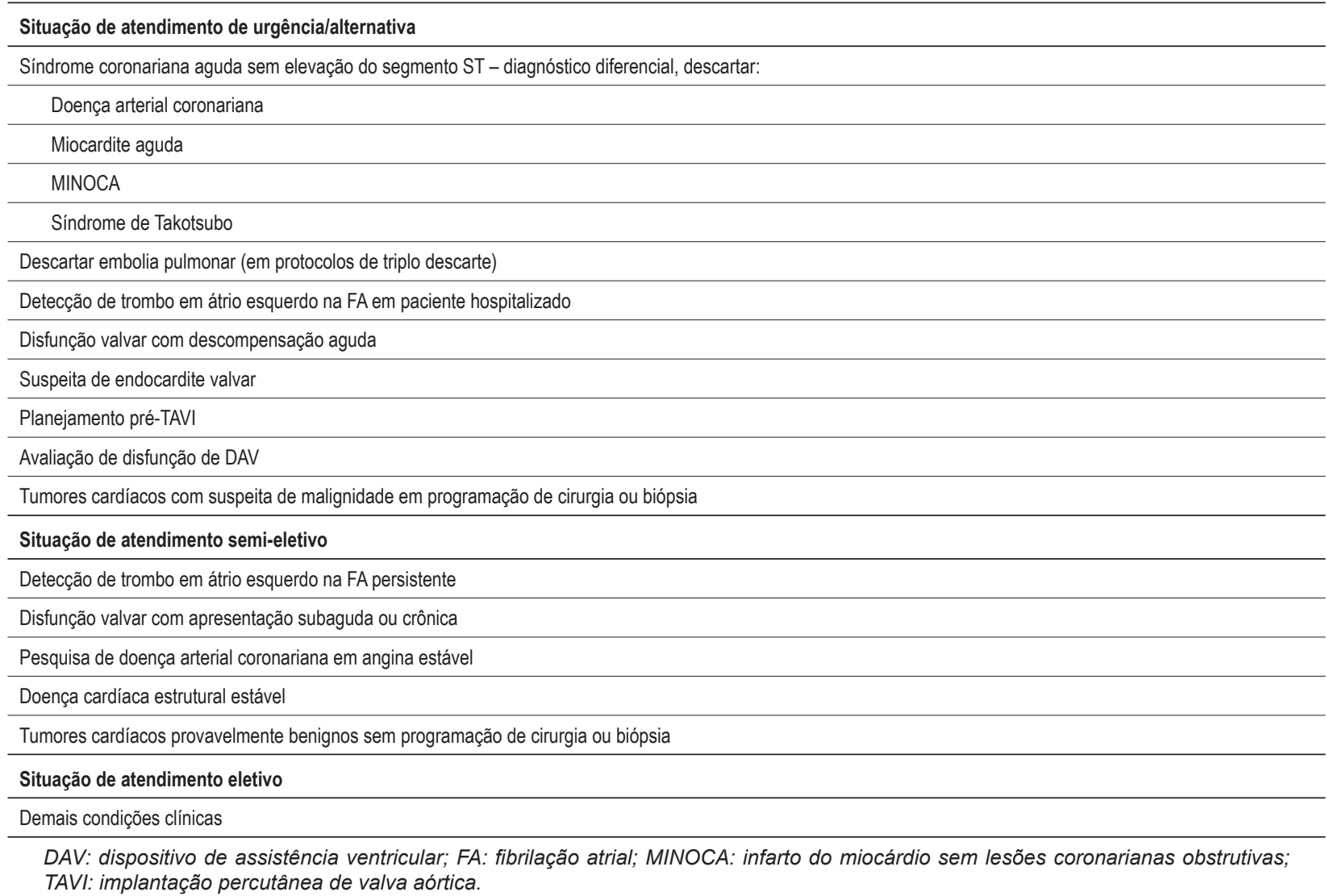

- O PET com 18F-FDG deve ser considerado para endocardite como uma alternativa ao ETE, que apresenta uma exposição muito alta ao risco de gotículas para os operadores.

Além das medidas implementadas no contexto da pandemia, a rápida evolução e o seu impacto no mundo podem resultar em uma possível escassez ou dificuldade de distribuição de medicamentos e radiofármacos. Sendo assim, um controle de fluxo mais restrito é essencial, principalmente durante o período de alto número de novos casos de COVID-19 ou em situações de possível disrupção da logística de distribuição das medicações.

\section{Hemodinâmica e Cardiologia Intervencionista}

\section{Classificação: Contato invasivo de vias aéreas}

Risco: Muito Alto Risco

\section{a. Procedimentos Eletivos}

\section{Recomendações Gerais}

- Pacientes eletivos devem seguir fluxos distintos no setor de hemodinâmica em relação aos casos emergenciais.
- Em serviços com mais de uma sala de intervenção, devese manter sala exclusiva para casos eletivos.

- Manter Heart Team atuante durante a pandemia e envolvido na fase de reabertura.

- Aplicar o Questionário de Sintomas e Exposição antes da realização de procedimentos intervencionistas eletivos (Suplemento A).

- No início do processo de reabertura, selecionar os pacientes com maior potencial de benefício com a intervenção coronária percutânea ou intervenção em cardiopatia estrutural (Tabela 9).

Apesar de controversa, a utilização de exames de RT-PCR para diagnóstico de COVID-19 em pacientes assintomáticos que internem no hospital para procedimentos eletivos pode ser considerada adequada para redução de risco de transmissão nosocomial. Nesses casos, pode-se coletar o swab nasofaríngeo/ orofaríngeo, em caráter ambulatorial, para RT-PCR para SARSCoV-2 nas 48 horas que antecedem os procedimentos, devendo a coleta ser realizada preferencialmente em regime domiciliar. Essa prática facilita a alocação hospitalar dos pacientes durante a internação, racionaliza a utilização de EPI específico e minimiza os riscos de exposição da equipe. Se a coleta de RT-PCR para SARS-CoV-2 não estiver disponível, sugerimos fluxograma alternativo (Figura 3). 
Tabela 9 - Pacientes com maior potencial de benefício com a intervenção

Doença coronariana sintomática de difícil manejo clínico

Doença coronariana e achados de alto risco em prova funcional

Doença coronariana e achados anatômicos de alto risco, como lesão obstrutiva grave do tronco da artéria coronária esquerda ou do terço proximal da artéria descendente anterior

Estenose aórtica grave sintomática ou assintomática com FEVE reduzida

Insuficiência mitral em CF III/IV e progressão recente, com queda recente da FEVE, ou nos serviços com programas estabelecidos de tratamento percutâneo da

insuficiência mitral por clip mitral

CF: classe funcional; FEVE: fração de ejeção de ventrículo esquerdo.

\section{Com exame RT-PCR para SARS-CoV-2}

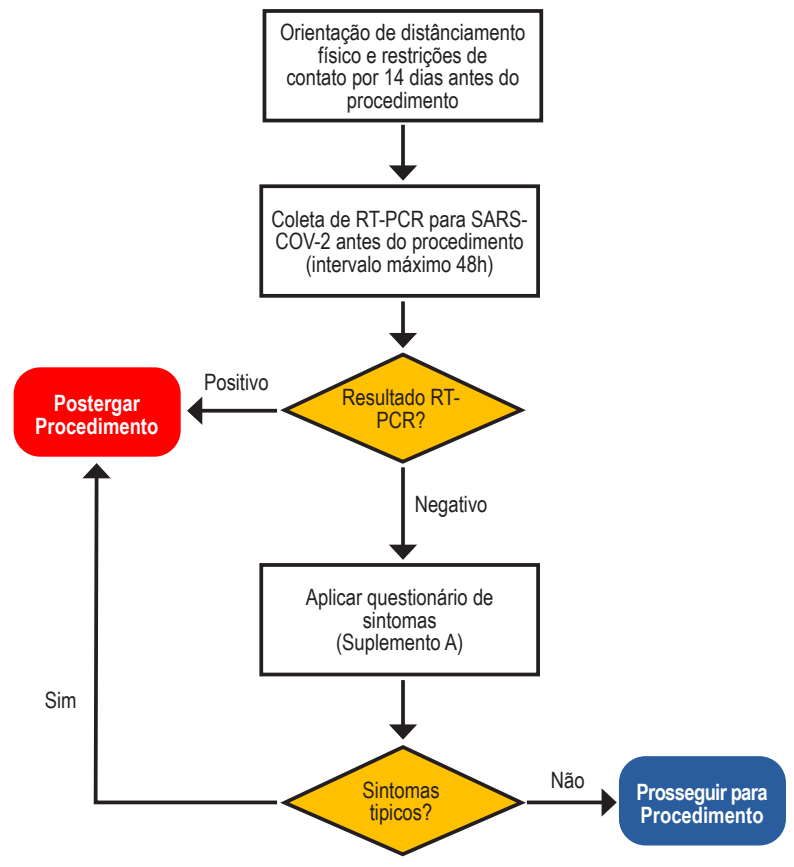

\section{Sem exame RT-PCR para SARS-CoV-2}

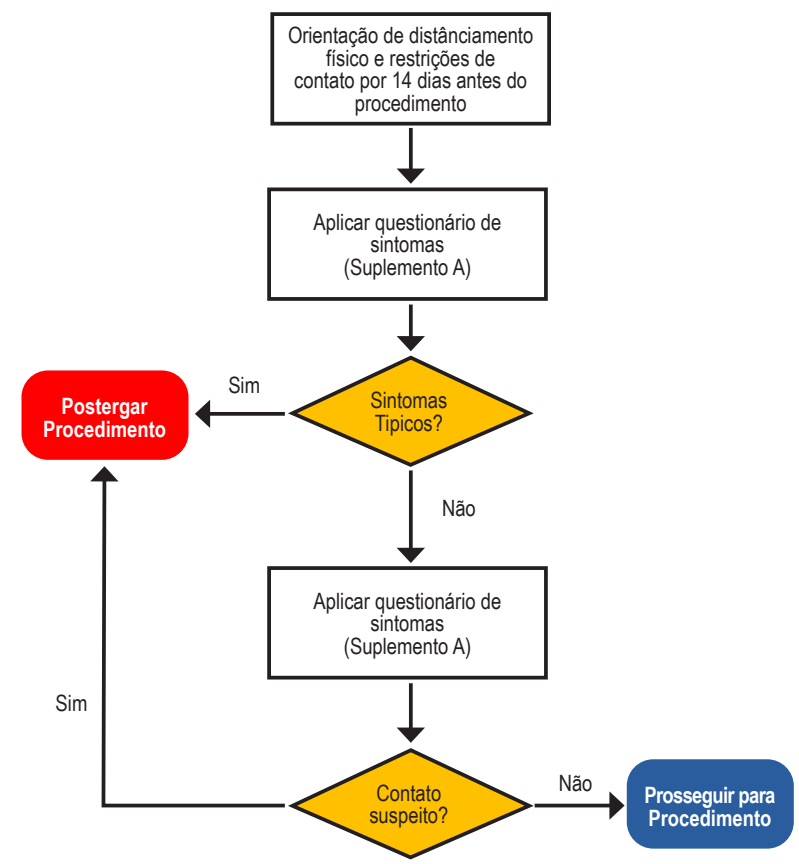

Figura 3 - Fluxograma de conduta para procedimentos eletivos de cardiologia intervencionista e eletrofisiologia de acordo com a presença e ausência do exame de RT-PCR para SARS-CoV-2.

\section{Recomendações Gerais}

- Obtenção de consentimento informado após esclarecimento dos riscos e benefícios do procedimento no contexto da pandemia.

- Recomenda-se adiar, por no mínimo 14 dias, os procedimentos eletivos em pacientes sintomáticos ou com RT-PCR para SARS-CoV-2 positivo. Em pacientes de perfil clínico $\mathrm{C}$ e $\mathrm{D}$, deve-se considerar o risco-benefício de se adiar a realização do procedimento até controle da pandemia.

- Em implantes de valva aórtica transcateter, preconizar a abordagem minimalista com sedação consciente quando factível, priorizando encurtamento do tempo de internação hospitalar e reduzindo a utilização do ETE.

\section{Recomendações Pré-procedimento}

1. Local com Coleta de RT-PCR Pré-internação de Rotina

- Recomenda-se coletar RT-PCR para SARS-CoV-2 por swab nasal e orofaríngeo em prazo máximo de 48 horas antes do procedimento. Preferencialmente oferecer coleta domiciliar.

- Todos os pacientes devem ser orientados quanto à manutenção de distanciamento social e restrição de contatos nos 14 dias que antecedem o procedimento.

- Realizar, mediante contato telefônico ou por meio eletrônico, rastreio de sintomas e exposição (Suplemento A) nas 48 horas que antecedem a realização do procedimento. 
- Se houver acompanhante no período de internação, aplicar Questionário de Sintomas e Exposição e solicitar RT-PCR.

- Se o teste de RT-PCR detectar a presença do vírus, aguardar no mínimo 14 dias com melhora dos sintomas há pelo menos 3 dias para reagendar o procedimento. Não é necessário coletar novo RT-PCR para liberação do procedimento, pois o exame poderá permanecer positivo mesmo com vírus inviável.

\section{Local sem Realização de RT-PCR Antes da Internação}

- Todos os pacientes devem ser orientados quanto à necessidade de isolamento domiciliar e restrição absoluta de contato nos 14 dias que antecedem o procedimento.

- Realizar rastreio de sintomas e de exposição de risco (Suplemento A) antes do exame para obter a melhor segurança.

\section{Recomendações Durante o Procedimento}

Utilização de EPI de nível 3 (precaução contra contato + aerossóis) para todos os operadores.

\section{Recomendações Pós-procedimento}

- Encaminhar pacientes para o setor de recuperação anestésica conforme resultado da triagem (área para COVID-19 positiva e área para COVID-19 negativa). Se não for possível, a recuperação anestésica poderá ser realizada na própria sala de procedimento.

- Priorizar alta no mesmo dia ou, caso isso não seja possível, minimizar o tempo de internação.

- Quando a intervenção ou exame for seguida de internação hospitalar, utilizar fluxo hospitalar apropriado e leitos reservados para pacientes sem COVID-19.

- Após a alta, como indicador de segurança, realizar o seguimento dos pacientes quanto ao surgimento de sintomas no período de até 10 dias após o procedimento. Caso o paciente desenvolva sintomas, deve-se realizar a busca de contatos hospitalares do paciente-índice.

\section{b. Procedimentos de Urgência e Emergência}

Com o número elevado de suscetíveis na população, a retomada dos programas de intervenções percutâneas eletivas ocorrerá concomitantemente com as admissões hospitalares relacionadas à infecção por SARS-CoV-2, que reconhecidamente aumenta o risco de fenômenos tromboembólicos e determina múltiplas manifestações cardiológicas, como síndromes coronarianas agudas, miocardites, infarto do miocárdio tipo II e arritmias ventriculares, além de cardiomiopatia de estresse (Síndrome de Takotsubo) desencadeada pela própria doença. Dessa forma, é fundamental a manutenção de um fluxo próprio para atendimento de casos suspeitos ou confirmados de COVID-19, bem como para atendimentos emergenciais de pacientes com síndromes coronarianas agudas com status infeccioso desconhecido e sem possibilidade de testagem.

\section{Recomendações Gerais}

- Reservar uma sala para casos de COVID-19 confirmada ou suspeita e para pacientes de emergência, em serviços com duas salas ou mais.

\section{Recomendações Pré-procedimento}

- Não retardar o atendimento dos casos de emergência, como infarto agudo do miocárdio (IAM) com supradesnivelamento do segmento ST;

- Pacientes com diagnóstico pré-hospitalar via telemedicina de IAM com supradesnivelamento do segmento ST e pacientes referenciados por outras unidades para angioplastia primária ou angioplastia de resgate devem ser encaminhados diretamente ao setor de hemodinâmica, evitando-se fluxo pelo pronto-atendimento.

\section{Recomendações Durante o Procedimento}

- Disponibilizar EPI de nível 3 (precaução contra contato + aerossóis) para toda a equipe.

- Manter equipe treinada em técnicas de paramentação e desparamentação.

- Manter equipe médica e equipe multidisciplinar em número reduzido no interior da sala.

- Reduzir materiais sobre as bancadas e checar tool box antes dos procedimentos para evitar a abertura da porta.

- Remover armários, quando possível, ou manter suas portas fechadas durante todo o procedimento.

- Em salas sem pressão negativa, minimizar a abertura da porta e utilizar áudio do sistema de comunicação para contato com o meio externo.

- Destinar um técnico no exterior da sala com paramentação de proteção completa para entrega de materiais com aberturas breves da porta;

- Usar sedação de modo parcimonioso para evitar instrumentalização da via aérea.

- Realizar entubação orotraqueal (IOT) com técnica de sequência rápida, quando necessário.

- Em pacientes com comprometimento progressivo da mecânica respiratória, priorizar IOT e evitar utilização de ventilação não invasiva e de cânula nasal de alto fluxo.

\section{Recomendações Pós-procedimento}

- Ao término do procedimento, encaminhar o paciente para internação em zona específica para COVID-19 confirmada ou para pacientes aguardando RT-PCR para COVID-19.

- Aguardar o transporte dentro da sala de hemodinâmica para evitar contaminação do ambiente de recuperação pósanestésica.

\section{Higienização Pós-procedimento}

- Realizar a desparamentação dentro da sala.

- Realizar limpeza terminal da sala de forma rotineira. 


\section{Eletrofisiologia}

\section{Classificação: Contato invasivo de vias aéreas}

\section{Risco: Muito Alto Risco}

\section{a. Procedimentos Eletivos}

Devem-se observar as recomendações gerais de reabertura do programa de eletivos descrita anteriormente para os procedimentos invasivos em hemodinâmica, com obtenção de consentimento informado considerando os riscos e os benefícios do procedimento e o contexto da pandemia, observando-se ainda fluxos distintos para os exames eletivos e os atendimentos de urgência/emergência.

Os exames/intervenções com maior grau de urgência (Tabela 9) e maior impacto prognóstico devem ser priorizados para reduzir o risco de morte e prevenir descompensações clínicas.

- Recomenda-se adiar procedimentos eletivos em pacientes sintomáticos ou com RT-PCR positivo recente mesmo que assintomáticos.

- Apesar de controversa, a utilização de exames de RT-PCR para diagnóstico de COVID-19 em pacientes assintomáticos admitidos para procedimentos eletivos em eletrofisiologia pode ser considerada adequada para redução de risco de transmissão nosocomial (Figura 3).

\section{b. Procedimentos de Urgência e Emergência}

Diante de cenários clínicos com risco iminente de descompensação hemodinâmica ou óbito (Tabela 10), pacientes com COVID-19 ou status infecioso desconhecido podem ser admitidos para intervenções de emergência. Nesses casos, devem ser observadas as recomendações de segurança da equipe em concomitância.

As recomendações de cuidados durante e após o procedimento são semelhantes àquelas apresentadas para serviços de hemodinâmica conforme descrito acima.

\section{Considerações Especiais Acerca dos Pacientes Envolvidos no Transplante Cardíaco}

A COVID-19 tem repercussões específicas para os pacientes envolvidos no contexto do transplante cardíaco, incluindo doadores e receptores, tanto na lista de espera como após o transplante. Como já conhecido, trata-se de uma população de risco aumentado para infecção por SARS-CoV-2 e progressão para doença grave em razão das comorbidades, do contato constante com unidades e profissionais de saúde e da imunossupressão. Por outro lado, trata-se de um perfil de alta adesão às recomendações médicas. ${ }^{20}$ Assim, são necessárias estratégias de prevenção e tratamento direcionadas. ${ }^{21}$

Com relação ao doador, devemos estar atentos à escolha de indivíduos não infectados, reconhecendo que muitos podem ser portadores assintomáticos/pré-sintomáticos/ oligossintomáticos e que os testes atuais têm limitações importantes. Assim:

- Recomenda-se realizar o teste RT-PCR para SARS-CoV-2 logo que consentida a doação de órgãos.

- Sempre que disponível, orienta-se a realização de TC de tórax para afastar achados radiográficos suspeitos de infecção.

- Se o resultado do RT-PCR for positivo, seus órgãos não devem ser utilizados para transplante.

Quando internados, os pacientes tanto da fila de espera como aqueles em pós-operatório de transplante:

- Devem ser mantidos em unidades "não COVID-19", reservando-Ihes atendimento por uma equipe multiprofissional que não tenha contato com casos positivos para infecção por SARS-CoV-2.

- Devem ter as visitas presenciais controladas e não recomendadas. A rotina de comunicação com familiares deve ser organizada.

\section{Tabela 10 - Classificação dos procedimentos de eletrofisiologia durante a pandemia de COVID-1919}

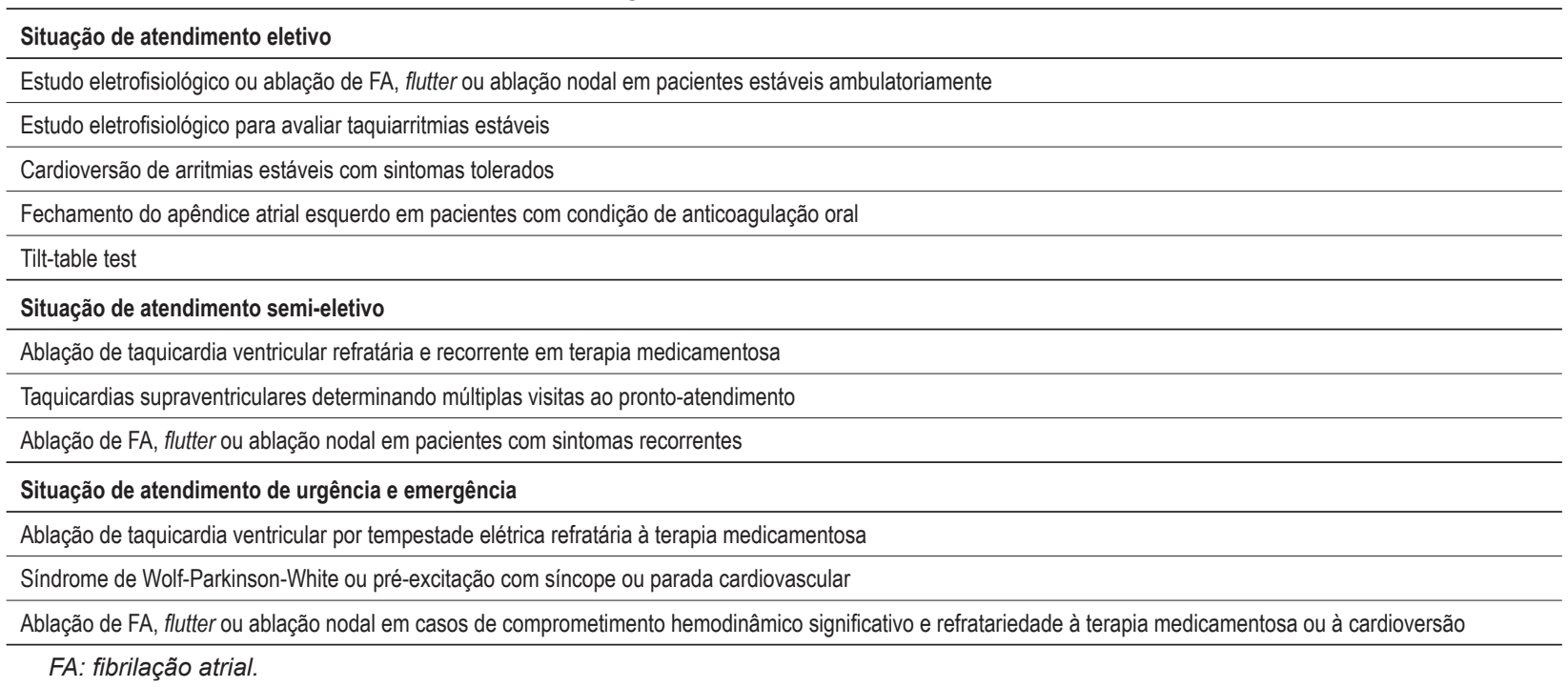


No contexto ambulatorial, deve-se manter a recomendação deste posicionamento:

- Reduzir visitas presenciais para pacientes estáveis e sem sintomas.

- Estimular o telemonitoramento dos níveis séricos dos imunossupressores.

- Postergar rotina de biópsia endomiocárdica em pacientes estáveis.

No paciente receptor de transplante cardíaco, em razão do status de imunossupressão sustentada, pode ocorrer manifestação típica (respiratória) e atípica (gastrointestinal) na infecção por SARS-CoV-2. Nesses casos, recomenda-se:

- Considerar reduzir a dose de inibidor de calcineurina (ciclosporina ou tacrolimus).

- Suspender temporariamente os antiproliferativos (micofenolato ou azatioprina).

\section{Orientações ao Paciente com Fatores de Risco para Infecção por SARS-CoV-2 e suas Repercussões Clínicas}

O cardiologista clínico cumpre um papel essencial no cuidado dos pacientes com infecção pelo SARS-CoV-2, devido à alta prevalência de fatores associados a maior risco de repercussões clínicas mais graves no contexto da infecção viral. Assim, o adequado controle dos fatores de risco tornase objetivo indispensável na continuidade do tratamento, na tomada de novas decisões e na orientação para redução do risco de contágio e de infecção.

Pacientes com Risco Aumentado para Formas Graves de Infecção por SARS-CoV-2

$\mathrm{Na}$ Tabela 6, foram apresentados os fatores de risco para formas graves de COVID-19. Esses pacientes devem ser avisados quanto à sua situação e à necessidade de continuidade do tratamento:

- Não alterar nem suspender o uso das medicações sem antes consultar seu médico.

- Manter um suprimento de medicamentos pelo menos mensal.

- Manter as vacinas atualizadas de acordo com o calendário de imunizações (em especial contra influenza e doença pneumocócica).

- Reforçar a importância de permanecer fisicamente ativo e praticar hábitos saudáveis, inclusive como medida de redução de risco de complicações da COVID-19.22 A prática de exercícios físicos dentro das normas de segurança recomendadas para que se evite o contágio por COVID-19 deve ser incentivada.

- O combate ao tabagismo deve ser fortemente recomendado, inclusive em populações de menor risco, como indivíduos jovens, tendo em vista o aumento da chance de complicações. ${ }^{23}$

- Nunca postergar a procura por pronto-atendimento em caso de qualquer sinal de alerta, como dor torácica, dispneia, sintomas de alteração de fala, marcha e/ou força muscular localizada ou outra condição que requeira atendimento imediato.

Tais recomendações visam consolidar a adesão ao tratamento e o controle de fatores de risco cardiovascular (em especial obesidade e tabagismo), uma estratégia que pode agregar valor adicional à redução do risco de complicações da COVID-19. ${ }^{24,25}$

Além disso, deve-se orientar a manutenção de medidas para diminuição do risco de contágio, tais como:

- Limitar as interações de proximidade física com outras pessoas, sempre que possível.

- Tomar precauções devidas ao interagir com outras pessoas:

- Distanciamento de pelo menos 2,0 m.

- Uso de máscara facial de tecido.

- Higiene das mãos com água e sabão ou álcool gel.

- Entrar em contato com seu médico em caso de febre, diarreia ou sintomas respiratórios.

- Em caso de suspeita de COVID-19, contraindicar a automedicação e orientar sobre os riscos.

- Evitar atividades nas quais não é possível tomar medidas de proteção, como situações onde o distanciamento social não pode ser mantido (reuniões em ambiente fechado, eventos).

- Evitar aproximação com outras pessoas que não estejam tomando medidas de proteção.

Cuidados após a Alta do Paciente Cardiológico e Retorno ao Trabalho após Infecção por SARS-CoV-2

Estudos indicam que até $20 \%$ dos pacientes apresentam alguma complicação cardiovascular durante a internação por COVID-19, entre elas arritmias, síndrome coronariana aguda e injúria miocárdica. ${ }^{21}$ Esses pacientes têm apresentação clínica da COVID-19 mais grave e mortalidade três vezes maior. Da mesma forma, esses pacientes podem enfrentar diversos obstáculos no ambiente domiciliar após a alta. Para aqueles com limitações funcionais após a alta, deve-se reforçar a necessidade de reabilitação.

- Física: muitos pacientes receberão alta necessitando de cuidados por limitações respiratórias ou cuidados em área de feridas/pressão. Também serão necessárias intervenções para recuperar a massa muscular e a capacidade funcional naqueles com neuromiopatia do paciente crítico.

- Psicológica e neuropsicológica: como resultado de suas experiências de doença e tratamento, pacientes em recuperação podem desenvolver adversidades psicológicas persistentes ou até mesmo comprometimento cognitivo.

- Socioeconômico: as necessidades e circunstâncias sociais e econômicas dos pacientes foram comumente afetadas pela pandemia. $\mathrm{O}$ impacto potencial de mudanças durante o isolamento também deve ser considerado.

Por esse motivo, nos pacientes que apresentaram manifestação cardiovascular grave da doença, deve-se considerar reavaliação na primeira semana após a alta hospitalar para verificação dos sintomas cardiovasculares, adesão medicamentosa e esclarecimento de dúvidas e dificuldades de readaptação às atividades rotineiras, levando-se em conta os 
procedimentos de reabilitação descritos abaixo. Ainda, o tempo mínimo para o retorno às atividades laborais deve seguir as diretrizes já existentes e levar em conta a funcionalidade após a alta e o tempo de isolamento mínimo necessário.

\section{Reabilitação Cardiovascular}

Estabelecida cientificamente como importante intervenção na prevenção secundária, a reabilitação cardiovascular é uma das medidas com indicação IA pela SBC em diversos contextos de cuidados na doença arterial coronariana, no pós-operatório de cirurgias cardíacas e na insuficiência cardíaca, tendo particular importância no período após a alta de internações por quadros agudos, como é o caso da COVID-19.

No atual momento, onde há necessidade de se cumprirem as diretrizes de distanciamento social e redução de mobilidade, destaca-se a urgência na implementação de modelos eficazes de combinação de atendimento presencial e de telemonitoramento remoto. No âmbito mundial, diferentes meios de comunicação têm sido utilizados nesse processo de reabilitação virtual (por exemplo, telefone/celular, aplicativos para smartphone, e-mail, mensagem de texto, páginas da Internet, videoconferências). No entanto, é essencial a avaliação individual do risco-benefício para os atendimentos à distância, como menor intensidade no treinamento físico intensivo, menor apoio social, padrões de treino remoto ainda em elaboração e preocupações de segurança em pacientes com maior risco. A adaptação do ambiente de reabilitação cardiopulmonar durante a pandemia de COVID-19 está detalhada na Tabela 11.

\section{Segurança dos Pacientes e Profissionais de Saúde na Pandemia}

Proteger pacientes e profissionais de saúde em todos os níveis deve ser o objetivo principal na retomada das atividades durante a pandemia. Estudos já demonstraram a alta taxa de contaminação entre profissionais da saúde, além do potencial papel desse grupo na disseminação da COVID-19, como superdisseminadores, tanto no ambiente de trabalho quanto na comunidade.

A higienização das mãos e o uso adequado do EPI são imprescindíveis para minimizar os riscos de contaminação dos trabalhadores de saúde pelo SARS-CoV-2. Desse modo, é de suma importância que toda a equipe receba treinamento sobre a utilização correta do EPI, com atenção especial à paramentação e à desparamentação, que devem ser padronizadas para reduzir o risco de contaminação. Toda a equipe deve receber capacitação e demonstrar habilidade para colocação, uso, retirada e descarte correto e seguro do EPI. ${ }^{3,26}$

A orientação de utilização do EPI específico deve ser baseada no risco biológico a que os profissionais estarão expostos durante as atividades e deve atender às seguintes recomendações:

- Regularização junto aos órgãos certificadores e à Anvisa;

- Utilização adequada, higienização ou descarte periódico, conforme recomendações técnicas;

- Inspeção, reparo e substituição de acordo com instruções do fabricante.

No entanto, além da segurança física da equipe, deve-se considerar também a segurança legal, psicológica, econômica e informacional.

\section{a. Segurança Física}

Assegurar a integridade física do profissional de saúde envolvido é uma das principais metas na implantação de medidas de retorno às atividades. Além do treinamento contínuo de toda a equipe, da aplicação diária do Questionário de Sintomas e Exposição em toda a equipe e do rastreamento de contatos de casos confirmados, são essenciais o fornecimento e o uso racional e sistemático de EPI.

\section{Seleção da Equipe no Retorno ao Trabalho}

Como os serviços voltarão de forma gradual à sua capacidade total, é importante selecionar para o retorno inicialmente os profissionais de saúde com menor risco e considerar a adequação do risco aos ambientes de trabalho onde o profissional é alocado.

Primeiramente, evidências sugerem que os profissionais mais jovens e sem fatores de risco sejam priorizados em ambientes de "contato próximo" e "invasivo de vias aéreas", onde o risco ocupacional de infecção por SARS-CoV-2 é maior. Por outro lado, profissionais idosos ou de meia-idade com fatores de risco devem ser encorajados, até momento oportuno, a manter-se em ambiente de atendimento remoto

Tabela 11 - Recomendações para a adaptação dos centros de reabilitação cardiopulmonar para a pandemia da COVID-19

\begin{tabular}{l}
\hline Aplicar o questionário de rastreamento de sintomas e contato (Suplemento A) e cancelar o atendimento presencial em caso de qualquer resposta positiva \\
\hline Uso obrigatório de máscaras cirúrgicas pelo paciente e pela equipe durante toda a permanência no centro de reabilitação \\
\hline Manter distância mínima de $2,0 \mathrm{~m}$, sempre que possível, durante o uso de aparelhos (cicloergômetro, esteira) \\
\hline Organizar sessões individuais ou reduzir o número de pacientes por atendimento o máximo possível \\
\hline Desinfecção sistemática do material utilizado antes e depois de cada atividade \\
\hline Utilizar programas mais curtos, concentrando os esforços nos componentes principais de cada paciente atendido \\
\hline Substituir, sempre que possível, as sessões presenciais por avaliação e monitoramento remotos, orientando os pacientes de acordo com o equipamento e com o meio \\
de comunicação mais adequado para o momento (telefone, mensagens de texto, e-mails, consultas por vídeo-chamada, plataformas e aplicativos dedicados) \\
\hline Promover estratégias especiais para a maioria dos imunocomprometidos, como pacientes transplantados cardíacos \\
\hline Interromper as atividades comunitárias que não respeitem as regras de distanciamento social \\
\hline
\end{tabular}


e/ou com distanciamento físico rigoroso. Para os demais casos, pode-se seguir a Tabela 12.

\section{Medidas de Controle de Transmissão e Isolamento de} Casos Suspeitos

O profissional de saúde que apresentar sintomas sugestivos de infecção por SARS-CoV-2 deve ser prontamente afastado. A seguir, deve-se realizar a investigação dos contatos dos 4 dias anteriores ao início dos sintomas. Os contatos devem ser monitorados, orientados a fazer quarentena por 10 dias do último contato e, caso disponível, realizar swab nasofaríngeo para pesquisa do vírus por RT-PCR.

Critérios para Retorno às Atividades Laborais após COVID-19

\section{- Casos suspeitos}

O profissional de saúde com quadro clínico suspeito de COVID-19 (RT-PCR negativo ou não coletado) poderá retornar às atividades após preenchidos ambos os critérios:

1. Pelo menos 3 dias (72 horas) após critério de recuperação clínica, definida como:

- Resolução da febre sem o uso de antitérmicos.

- Melhora dos sintomas respiratórios (tosse, falta de ar) E

2. Pelo menos 10 dias desde o início dos sintomas.

\section{- Casos confirmados}

- Sintomáticos

O profissional de saúde com confirmação de COVID-19 (RT-PCR positivo) poderá retornar às atividades após preenchidos ambos os critérios:

1. Pelo menos 3 dias (72 horas) após critério de recuperação clínica, definida como:

- Resolução da febre sem o uso antitérmicos.

- Melhora dos sintomas respiratórios (tosse, falta de ar), E

2. Pelo menos 10 dias desde o início dos sintomas.

\section{- Assintomáticos}

Devido à ausência de sintomas, não é possível avaliar onde esses indivíduos estão no curso de sua doença. Assim, caso haja confirmação por RT-PCR positivo em assintomático, o critério para liberação do isolamento será:

$>$ Pelo menos 10 dias do resultado do teste positivo.

Para pacientes assintomáticos confirmados por testes sorológicos, não há orientação clara sobre o retorno às atividades após testes positivos. No entanto, levando-se em conta a segurança do ambiente de trabalho, deve-se considerar a estratégia mais segura. Logo, sugere-se:

$>$ Sorologia $\lg M$ ou $\lg A$ reagente ou $\operatorname{lgG} / \lg M$ reagentes retorno após 10 dias do teste.

> Sorologia IgG reagente-sem necessidade de afastamento.

Aconselha-se consultar especialistas em doenças infecciosas para definir tempo de retorno ao trabalho para os indivíduos que possam permanecer transmissores por mais de 10 dias (por exemplo, imunocomprometidos).

\section{Residência Médica e Complementação especializada}

Os estagiários são uma parte importante dos programas e serviços de cardiologia em boa parcela do país. Durante a pandemia do COVID-19, muitos deles foram transferidos de seus estágios de imagem para o atendimento clínico de pacientes com COVID-19 em hospital e unidades de terapia intensiva.

No retorno às atividades, sugere-se que os iniciantes sejam deslocados para divisões onde sua inexperiência não aumente o tempo de exposição da equipe ao paciente. A educação precisa ser revisada buscando novos métodos de aprendizado, incluindo abordagens de aprendizado baseadas em videoconferências e treinamento remoto.

\section{b. Segurança Legal}

Pacientes admitidos devem assinar previamente termo de consentimento, de preferência contendo informações de que estão cientes que o procedimento está sendo realizado durante epidemia de COVID-19, com riscos inerentes ao procedimento e ao momento excepcional. Também são recomendados documentação e armazenamento dos questionários diários de sintomas e exposição tanto dos profissionais de saúde como dos pacientes, para caso haja necessidade futura, assim como documentação por escrito de rotinas de precaução contra transmissão consideradas pela equipe responsável pelo atendimento.

Tabela 12 - Classificação das prioridades a serem consideradas para retorno da equipe de trabalho

\begin{tabular}{lccc}
\hline & Jovem, sem fator de risco & $\begin{array}{c}\text { Meia-idade ou jovem com } \\
\text { fator de risco* }\end{array}$ & $\begin{array}{c}\text { Idoso ou meia-idade com } \\
\text { fator de risco* }\end{array}$ \\
\hline Contato invasivo de vias aéreas & 1 & 3 & 2 \\
\hline Contato próximo & 1 & 2 & 2 \\
\hline Contato moderado & 1 & 1 & 1 \\
\hline Sem contato / Remoto & 1 & 3 & 2 \\
\hline
\end{tabular}

Prioridade 1 - retornar imediatamente

Prioridade 2 - retornar após esgotados os profissionais de saúde em prioridade 1

Prioridade 3 - Não retornar a princípio, salvo extrema necessidade

*Os fatores de risco estão listados na Tabela 4 


\section{Profissionais de Saúde em Situação de Risco}

Como citado anteriormente no tópico de Seleção da equipe no retorno às atividades, alguns profissionais não retornarão de imediato ao trabalho. Nesses casos de afastamento (Tabelas 6 e 12) ou durante o período de sintomas, isolamento e reabilitação em caso de infecção por SARS-CoV-2, faz-se necessária uma rede de apoio entre os especialistas para encaminhamento imediato dos pacientes sob sua custódia.

\section{c. Segurança Psicológica}

À medida que a situação de pandemia continua, são necessárias estratégias para apoiar psicologicamente os profissionais de saúde, em especial o grupo mais suscetível a sofrimento psicológico. O suporte psicológico pode incluir serviços de aconselhamento e desenvolvimento de sistemas de apoio entre colegas. São também parte do plano: ${ }^{27,28}$

- Monitorar constantemente a equipe quanto ao bem-estar, em especial se for necessário trabalhar em jornadas prolongadas ou quando remanejados para áreas desconhecidas.

- Facilitar o acesso aos serviços de saúde mental e de apoio psicossocial.

- Manter busca ativa de profissionais em condições psicológicas comprometidas e em situação de burnout.

- Exigir o feedback periódico dos colaboradores.

- Fornecer atualizações de informações precisas a todos os funcionários.

- Considerar rodízios das funções de maior estresse físico/ emocional com as de menor estresse.

\section{d. Segurança Econômica}

No momento atual, os custos crescentes com o cuidado ao paciente com COVID-19, aliados à receita reduzida, pressionam financeiramente as instituições de saúde tanto no ambiente público como na iniciativa privada. É essencial que o comitê diretor mantenha atualizado de maneira constante o planejamento financeiro, negociando os repasses públicos no ambiente do Sistema Único de Saúde, ainda mais sobrecarregado nessa pandemia, e assegurando-se de acordo com a previsão de receitas quando na saúde suplementar. Ênfase particular deve ser dada ao aumento de custos associados a adaptação ambiental, uso de EPI e redução da capacidade de atendimento para garantir o distanciamento físico dos pacientes durante o fluxo no serviço de saúde.

\section{e. Segurança Informacional}

O combate a notícias falsas e o oferecimento de uma literatura de saúde apropriada aos pacientes são missões do cardiologista e da equipe multidisciplinar. A SBC tem emitido informes técnicos orientados ao cardiologista e aos pacientes.
A Organização Mundial de Saúde e entidades governamentais têm mostrado sua preocupação sobre a "infodemia" (com a propagação de notícias falsas) e seus impactos sobre a saúde física e psicológica dos pacientes.

É de responsabilidade da equipe de saúde manter-se atualizada e fornecer aos pacientes informações claras, objetivas e embasadas em fontes seguras para evitar a propagação de informações incorretas, incompletas, mal interpretadas ou falsas.

\section{Suplemento A}

Questionário de Sintomas e Exposição para ser aplicado antes da realização de procedimentos intervencionistas eletivos

\section{Questionário de sintomas:}

Nos últimos 14 dias você apresentou algum desses sintomas?

Sintomas maiores (basta 1 para suspeita):
$\square$ Febre
Tosse
Falta de ar
Confusão mental
Perda da sensação de gosto / cheiro

Sintomas menores (são necessários 2 para suspeita):

$\square$ Fadiga/cansaço
$\square$ Diarreia
$\square$ Nariz escorrendo
$\square$ Náusea e/ou vômitos
$\square$ Dor de garganta
$\square$ Dor de cabeça
$\square$ Conjuntivite
$\square$ Outro:

\section{Questionário de Exposição:}

1. Nos últimos 14 dias você teve contato, por mais de 15 minutos e a uma distância menor que 2,0 m, com alguma pessoa diagnosticada ou identificada pelo médico como suspeita de COVID-19?
$\square \mathrm{SIM}$
$\mathrm{NÃO}$

2. Nos últimos 14 dias você esteve internado em algum serviço de saúde?

$\square$ SIM NÃO

3. Se profissional de saúde: Você esteve em contato sem uso de EPI com pacientes com suspeita ou confirmação de COVID-19?

$\square \mathrm{SIM} \quad \square \mathrm{NÃO}$ 


\section{Referências}

1. Huang C, Wang Y, Li X, Ren L, Zhao J, Hu Y, et al. Clinical features of patients infected with 2019 novel coronavirus in Wuhan, China. Lancet. 2020 Feb;395(10223):497-506.

2. Chan JF-W, Yuan S, Kok K-H, To KK-W, Chu H, Yang J, et al. A familial cluster of pneumonia associated with the 2019 novel coronavirus indicating person-to-person transmission: a study of a family cluster. Lancet. 2020 Feb;395(10223):514-23.

3. Liu Y, Ning Z, Chen Y, Guo M, Liu Y, Gali NK, et al. Aerodynamic analysis of SARS-CoV-2 in two Wuhan hospitals. Nature. 2020 Jun;582(7813):557-60.

4. World Health Organization.(WHO) Transmission of SARS-CoV-2: implications for infection prevention precautions [Internet]. 2020 [cited 2020 Jul 11]. Available from: https://www.who.int/publications/i/item/ modes-of-transmission-of-virus-causing-covid-19-implications-for-ipcprecaution-recommendations

5. van Doremalen N, Bushmaker T, Morris DH, Holbrook MG, Gamble A, Williamson BN, et al. Aerosol and Surface Stability of SARS-CoV-2 as Compared with SARS-CoV-1. N Engl J Med. 2020 Apr 16;382(16):1564-7.

6. Chen J, Qi T, Liu L, Ling Y, Qian Z, Li T, et al. Clinical progression of patients with COVID-19 in Shanghai, China. J Infect. 2020 May;80(5):e1-6.

7. Lechien JR, Chiesa-Estomba CM, De Siati DR, Horoi M, Le Bon SD, Rodriguez A, et al. Olfactory and gustatory dysfunctions as a clinical presentation of mild-to-moderate forms of the coronavirus disease (COVID-19): a multicenter European study. Eur Arch Otorhinolaryngol. 2020 Aug;277(8):2251-61.

8. Pan L, Mu M, Yang P, Sun Y, Wang R, Yan J, et al. Clinical Characteristics of COVID-19 Patients With Digestive Symptoms in Hubei, China: A Descriptive, Cross-Sectional, Multicenter Study. Am J Gastroenterol. 2020 May; 115(5):766-73.

9. Flaxman S, Mishra S, Gandy A, Unwin H, Coupland H, Mellan T, et al. Report 13: Estimating the number of infections and the impact of nonpharmaceutical interventions on COVID-19 in 11 European countries [Internet]. Imperial College London; 2020 Mar [cited 2020 Jul 12]. Available from: http://spiral.imperial.ac.uk/handle/10044/1/77731.

10. Imperial College COVID-19 Response Team, Flaxman S, Mishra S, Gandy A, Unwin HJT, Mellan TA, et al. Estimating the effects of nonpharmaceutical interventions on COVID-19 in Europe. Nature [Internet]. 2020 Jun 8; online ahead of print .Available from: http://www.nature. com/articles/s41586-020-2405-7

11. Solomon MD, McNulty EJ, Rana JS, Leong TK, Lee C, Sung S-H, et al. The Covid-19 Pandemic and the Incidence of Acute Myocardial Infarction. N Engl J Med. 2020 May 19;NEJMc2015630.online ahead of print.

12. De Filippo O, D'Ascenzo F, Angelini F, Bocchino PP, Conrotto F, Saglietto A, et al. Reduced Rate of Hospital Admissions for ACS during Covid-19 Outbreak in Northern Italy. N Engl J Med. 2020 Jul 2;383(1):88-9.

13. Woolf SH, Chapman DA, Sabo RT, Weinberger DM, Hill L. Excess Deaths From COVID-19 and Other Causes, March-April 2020. JAMA [Internet]. 2020 Jul 1 [cited 2020 Jul 10]; online ahead of print. Available from: https://jamanetwork.com/journals/jama/fullarticle/2768086

14. U.S. Department of Labor OS and HA. Guidance on Returning to Work [Internet].[Cited in 2020 Apr 18]. Available from: https://www.osha.gov/ Publications/OSHA4045.pd

15. Brasil. Ministério da Saúde. Secretaria de Vigilância em Saúde, Ministério da Saúde. Recomendações de proteção aos trabalhadores dos serviços de saúde no atendimento de COVID-19 e outras síndromes gripais [Internet]. 2020 [cited 2020 Jul 12]. Available from:
https://portalarquivos.saude.gov.br/images/pdf/2020/April/16/01 recomendacoes-de-protecao.pdf

16. Brasil. Ministério da Saúde. Agência Nacional de Vigilância Sanitária. Nota técnica GVIMS/GGTES/ANVISA No 04/2020 - Orientações para serviços de saúde: medidas de prevenção e controle que devem ser adotadas durante a assistência aos casos suspeitos ou confirmados de infecção pelo novo coronavírus (SARS-CoV-2). [Internet]. 2020 [cited 2020 Jul 11]. Available from: http://portal. anvisa.gov.br/documents/33852/271858/Nota + Técnica $+n+04$ 2020+GVIMS-GGTES-ANVISA-ATUALIZADA/ab598660-3de4-4f148e6f-b9341c196b28

17. Lopes MACQ, Oliveira GMM de, Ribeiro ALP, Pinto F, Rey $\mathrm{HCV}$, Branda o AA, et al. Guidelines os the Brazilian Society of Cardiology on Telemedicine in Cardiology - 2019. Arq Bras Cardiol.201(:113(5):1006-56.

18. Zoghbi WA, DiCarli MF, Blankstein R, Choi AD, Dilsizian V, Flachskampf FA et al. Multimodality Cardiovascular Imaging in the Midst of the COVID-19 Pandemic. JACC Cardiovasc Imaging. 2020 Jul;13(7):1615-26.

19. Lakkireddy DR, Chung MK, Gopinathannair R, Patton KK, Gluckman TJ Turagam M, et al. Guidance for Cardiac Electrophysiology During the COVID-19 Pandemic from the Heart Rhythm Society COVID-19 Task Force; Electrophysiology Section of the American College of Cardiology and the Electrocardiography and Arrhythmias Committee of the Counci on Clinical Cardiology, American Heart Association. Heart Rhythm. 2020;S1547-5271(20)3289-7 online ahead of print.

20. Ren Z-L, Hu R, Wang Z-W, Zhang M, Ruan Y-L, Wu Z-Y, et al. Epidemiologic and clinical characteristics of heart transplant recipients during the 2019 coronavirus outbreak in Wuhan, China: A descriptive survey report. J Heart Lung Transplant. 2020 May;39(5):412-7.

21. DeFilippis EM, Farr MA, Givertz MM. Challenges in Heart Transplantation in the Era of COVID-19. Circulation. 2020 Jun 23;141(25):2048-51.

22. Liu M, Cheng S-Z, Xu K-W, Yang Y, Zhu Q-T, Zhang H, et al. Use of personal protective equipment against coronavirus disease 2019 by healthcare professionals in Wuhan, China: cross sectional study. BMJ 2020 Jun; doi:10.1136/bmj.m3195

23. Tan BYQ, Chew NWS, Lee GKH, Jing M, Goh Y, Yeo LLL, et al. Psychological Impact of the COVID-19 Pandemic on Health Care Workers in Singapore. Ann Intern Med. 2020 Apr 6;M20-1083.online ahead of print.

24. World Health Organization.(WHO). Mental health and psychosocial considerations during the COVID-19 outbreak [Internet]. 2020 [cited 2020 Jul 11]. Available from: https://www.who.int/docs/ default-source/coronaviruse/mental-health-considerations. pdf?sfvrsn=6d3578af_2

25. Wahid A, Manek N, Nichols M, Kelly P, Foster C, Webster P, et al. Quantifying the Association Between Physical Activity and Cardiovascular Disease and Diabetes: A Systematic Review and MetaAnalysis. J Am Heart Assoc. 2016 14;5(9):e002495. doi:10.1161

26. Adams SH, Park MJ, Schaub JP, Brindis CD, Irwin CE. Medical Vulnerability of Young Adults to Severe COVID-19 IIIness-Data From the National Health Interview Survey. J Adolesc Health Off Publ Soc Adolesc Med. 2020 Jul 9;S1054-139X(20)30338-4

27. Guo T, Fan Y, Chen M, Wu X, Zhang L, He T, et al. Cardiovascula Implications of Fatal Outcomes of Patients With Coronavirus Disease 2019 (COVID-19). JAMA Cardiol .2020;5(7):1-8. online ahead of print.

28. Shi S, Qin M, Shen B, Cai Y, Liu T, Yang F, et al. Association of Cardiac Injury With Mortality in Hospitalized Patients With COVID-19 in Wuhan, China. JAMA Cardiol .2020;5(7):802-10. online ahead of print. 